Wang, Lixin, and Pauline Sebillaud. 'The Emergence of Early Pottery in East Asia: New Discoveries and Perspectives'. Journal of World Prehistory 32, no. 1 (2019): 73-110. https://doi.org/10.1007/s10963-018-9126-y.

\title{
The Emergence of Early Pottery in East Asia: New
}

Discoveries and Perspectives

Lixin Wang ${ }^{1} \cdot$ Pauline Sebillaud $^{2}$

\begin{abstract}
The appearance of the oldest pottery in the world is a major focus of Early Neolithic archaeology. So far, most discoveries of early pottery have occurred in South China, North China, the Russian Far East, Japan and Korea. The discovery of very thick, low-fired, fibre-tempered pottery dated from around 10,000 BP at the Houtaomuga Site, in Jilin Province, fills an important gap in the distribution of early pottery in northeast China. Based on multi-disciplinary research and an important series of dates, this article establishes the chronology of the early pottery remains discovered at the Houtaomuga Site and their morphological and technical characteristics, and sheds light on their function. Finally, the authors compare them to the other early pottery sherds discovered in the surrounding region, and throughout East Asia, in order to discuss the significance of this discovery and its implications for the subsistence mode developed in the northwest of the Jilin Province at the very beginning of the Neolithic.

Keywords Early Neolithic $\cdot$ Pottery $\cdot$ Chronology $\cdot$ Northeast China $\cdot$ Northeast Asia
\end{abstract}

\section{Introduction}

Understanding the emergence of pottery is one of the oldest problems in archaeology. In many areas, it has been a defining feature of the Neolithic, often alongside sedentism, agriculture, animal husbandry, the use of ground stone tools and so forth (Underhill 1997, p. 105). Though it is increasingly clear that these traits did not always develop simultaneously, the desire to maintain the utility of pottery as a marker of social change remains strong (Hommel 2017).

Since the 1960s, pottery dating from around 10,000 years BP has been successively discovered in the Japanese archipelago, around Lake Baikal, in the Russian Far East and in South and North China. But northeast China, a key part of Northeast Asia, for a long time produced no discovery of early pottery prior to $10,000 \mathrm{BP}$ (Barnes 1999). This article will first present the most recent discoveries of early pottery at the Houtaomuga Site, then review the previous early pottery discoveries in East Asia to discuss the perspectives opened by this discovery.

\section{New Discoveries in Northeast China: The Houtaomuga Site}

Northeast China can be geographically defined as the area drained by rivers flowing

\footnotetext{
1 Research Center on Chinese Frontier Archaeology, Jilin University, Kuangyaming Building, Qianjin Avenue 2699, Changchun City 130012, Jilin Province, China

2 CNRS, East Asian Civilisations Research Centre - CRCAO UMR 8155, Paris, France ; Research Center on Chinese Frontier Archaeology, Jilin University, Kuangyaming Building, Qianjin Avenue 2699, Changchun City 130012, Jilin Province, China
} 
into the northern part of the Bohai Bay (Shelach 2000, p. 373) (Fig. 1). It includes the modern Chinese provinces of Heilongjiang, Jilin, Liaoning and the eastern part of Inner Mongolia. The summer is hot, dry and windy, and the winter is long and harsh. The growing season is quite short. During the Last Glacial Maximumaround 21,000 BP, followed by amelioration and complex variations up to 11,500 $\mathrm{BP}$ - this region had a cold steppic environment. These conditions improved slightly between 10,500 and 8000 BP (Shelach 2000, p. 375). The centre of China's northeast region is a vast alluvial plain formed by the Songhua River, a tributary of the Heilongjiang (Amur) River, and the Nen River. The valley of the middle and lower course of the Nen River has such a flat lowland topography that the rivers do not flow smoothly, but form numerous lakes and swamps. Yueliang and Xinhuang are two conjoined lakes formed where the Tao'er River (third-tier tributary of the Amur River), coming from the northwest, flows into the Nen River, forming a large body of water that today measures at least 2000 ha.

The Houtaomuga Site in Da'an City is located on a long and narrow hill on the southeast shore of Lake Xinhuang. The site has a total surface area of 1,410,000 m2 and shows a high density of finds across an area of 550,000 m2. These scatters include features and material from all the periods between the Early Neolithic and the Liao-Jin period (9th to 13th c. AD).

This article aims to establish the dates of the early pottery remains discovered at Houtaomuga, and their morphological and technical characteristics, to shed light on their function, and finally, to compare them to the other early pottery in East Asia.

\section{Methodology and Dates}

Methods

The Houtaomuga Site was excavated over five seasons between 2011 and 2015 (Wang et al. 2012, 2013). The archaeological team was composed of researchers in numerous fields from the Research Center on Chinese Frontier Archaeology of Jilin University, the Jilin Province Archaeological Research Institute, the French Ecole Pratique des Hautes Etudes, the University of Oregon and the University of Tokyo. Wheeler squares and open-area excavation were both used, all artifacts were collected and recorded by stratigraphic units, and all soil has been screened for microliths and small animal remains. Flotation samples were also taken in each stratigraphic unit in order to systematically collect paleobotanical remains. During the excavation, all the topographic information was recorded using a total station and photogrammetry for 3D rendering. All the data have been systematically entered into a database (Wang et al. 2016).

Faunal, floral and human remains have been analyzed by archaeozoology, paleobotany and bioarchaeology specialists (Xiao 2014; Zhang et al. 2015; Merrett et al.

2015), and samples have been taken for ancient DNA, as well as carbon and nitrogen isotope analysis. The paleoenvironment and geomorphology of the site have also been studied. Research on clay provenance, firing temperature, organic residue and production technique are still in progress.

The occupation of the site can be divided into seven phases (Jilin 2016). The 
first phase belongs to a transition period between the late Paleolithic and the Early Neolithic. Based on the systematic intra-site survey, the remains of phase I are distributed across an area measuring around 22,500 $\mathrm{m} 2$ (Liu et al. 2016). In 2011 and 2012, in the excavation of zone AIII of the site, the third layer was found to be a stratigraphic unit belonging to phase I. Several additional features from phase I were uncovered, including four ditches, 15 pits and one burial. These features are distributed across a surface measuring around $1000 \mathrm{~m} 2$. Features from phase I yielded over two thousand pottery sherds of various sizes.

Fig. 1 Map showing the location of early pottery sites in East Asia

Dates

A relative chronology was initially developed that was based on a pottery typology linked to observed site-stratigraphic relations, and which was refined through comparison between contexts on site and those within the region as a whole. Subsequently, five samples of carbonized residue adhering to ceramic surfaces, three samples of organic fibre-tempered pottery sherds, and samples from human and animal bones discovered with the early pottery were selected for $14 \mathrm{C}$ dating.

Some collateral evidence pointed to very early dates. The soil from the layers and features belonging to phase I has a light grey-yellow colour, very close to the colour of the underlying fine and sandy geological substrate. This soil all lies beneath layer 2, which is composed of black-grey fine and sandy Phaeozems, showing that the early stratigraphic units must have been formed before the warming phase of the Holocene. Moreover, the human bones from the phase I burial had already reached a certain degree of petrification.

According to recent research on the chronology of early pottery in the Russian Far East and Siberia, the ${ }_{14} \mathrm{C}$ dates obtained from organic materials used as temper in pottery paste and the ${ }_{14} \mathrm{C}$ dates obtained from wood charcoal are quite close (Kuzmin 2002). However, the recent results of a series of dates obtained by Japanese researchers also show that carbonized organic materials adhering to ceramics can give ${ }_{14} \mathrm{C}$ dates which are several centuries older than associated wood charcoal samples, with a discrepancy which could be as large as 1000-1500 years (Kunikita et al. 2014); this is why the time frame should be carefully verified and why we insisted on obtaining dates from a variety of types of samples.

Fibre-tempered pottery sherds from stratigraphically secure contexts were analyzed at the Xi' an Accelerator Mass Spectrometry Center of the Chinese Academy of Science, the National Laboratory of Nuclear Physics and Nuclear Technology of Beijing University (Table 1), and the Technology Laboratory of the Human Sciences Department at the University of Tokyo (Table 2). The half-life employed in the analysis is 5568 years, with a degree of confidence of 95.4\%) (Kunikita et al. in press). Synthesizing the ${ }_{14} \mathrm{C}$ data for the remains of Houtaomuga phase I, we deduce that the remains from this period can be reliably ascribed to the timeframe 12,900-11,100 BP.

The remains of Houtaomuga phase I contain the earliest pottery discovered so far 
in northeast China, and fill the gap in the distribution of early pottery dating from over 10,000 years BP in this region. These remains bear a resemblance to all the Early Neolithic cultures in the vast surrounding area, but the paste, the shapes of the objects and the decorative patterns are also different from all the previously known archaeological cultures. This indicates the existence of a new archaeological culture, which we propose to call the 'culture of Houtaomuga phase I', the pottery features of which are presented in the next section.

\section{The Pottery}

The Forms, Decoration and Composition of Houtaomuga Phase I Ceramics Most of these sherds are tempered with vegetable fibres, and have a grey-brown or yellow-brown outer surface and a black core paste. The recognizable object shapes are large cylindrical jars (tongxing guan), large-opening curved-belly jars (dakou qufu guan) and bowls (bo). Most of these containers must have had a wide belly and a large opening with a comparatively small bottom, an ideal shape for cooking pots (Skibo 2013, pp. 28-29). Only one bowl has been fully reconstructed. Most of the pots have a flat or slightly concave bottom (Fig. 2-16). Their walls are very thick, mostly between 0.8 and $1.5 \mathrm{~cm}$.

Apart from a very small number of sherds with a smoothed surface, the vast majority of these pots have surface decoration covering most of the vessel. Most of the patterns are comb-tooth-shaped dots made by stamp impressions from a blunt instrument with rather thick, flaked-shaped carved teeth. The patterns are horizontally oriented chevrons, parallel short lines and short arc lines, often leaving rather deep impressions $(2-3 \mathrm{~mm})$ on the outer surface of the objects. Some patterns were made by a thin flaked-shaped toothed instrument, for instance, parallel oblique lines, parallel arcs and zigzags, which left rather shallow impressions. There are also a small number of comb-tooth-shaped thin line patterns, comb-tooth vertical lines, and comb-tooth wave patterns in lines, where the tooth impressions are finely woven and uninterrupted, looking as if they were made by the impression of a rolling tool.

There is also a single instance of reverse round patterns, pits made by impressing a stamp on the outer surface of the pottery before it was totally dried, leaving protuberances at the corresponding point on the interior surface of the object (Fig. 2-9 to 17). This type of all-over surface treatment, removing any smooth surface, could have increased the vessel's resistance to thermal shock by limiting the spread of cracks (Schiffer et al. 1994; Skibo 2013, p. 48).

Table $1{ }_{14} \mathrm{C}$ dates of the Houtaomuga phase I samplesnanalyzed at Xi'an and Beijing

(human bones)

Feature no. Material Calibrated age (cal. BP)

11DHAIIIG18 Fibre-tempered pottery

sherds

$12,940-12,850$

11DHAIIIH248 Dog hip bone 11,760-11,270

11DHAIIIM45 Human bones 11,235-11,145 
Table $2{ }_{14} \mathrm{C}$ dates of the Houtaomuga phase I samples analyzed at the University of Tokyo (Calibrated ages are calculated using the IntCal13 data and OxCal v 4.2.4 software)

Feature no. Material ${ }_{14} \mathrm{C}$ age (BP) $\delta 13 \mathrm{C}(\%) \delta 15 \mathrm{~N}(\%) \mathrm{C}(\%) \mathrm{N}(\%) \mathrm{C} / \mathrm{N}$ Calibrated age $(95.4 \%$

confidence) (cal. BC)

Calibrated age $(95.4 \%$

confidence) (cal. BP)

12DHAIIIH143 Potsherd 10,550 $\pm 50-25.83 .71 .80 .115 .6$ 10,716-10,446 (95.4\%) 12,665-12,395 (95.4\%)

11DHAIIIT1006 Potsherd 10,460 $\pm 50-31.14 .94 .60 .222 .6$ 10,608-10,183 (95.4\%) 12,557-12,132 (95.4\%)

12DHAIIIH233 Charred residues (outer rim) 10,060 $\pm 50-26.0----9980-9943$ (1.6\%) 11,929-11,892 (1.6\%)

9875-9381 (93.8\%) 11,824-11,330 (93.8\%)

12DHAIIIG22 Charred residues and clay (inner rim) 10,820 $\pm 130-25.8----11,082-10,582(95.1 \%) 13,031-12,531$

$(95.1 \%)$

$10,504-10,496(0.3 \%) 12,453-12,445(0.3 \%)$

12DHAIIIH189 Charred residues (outer rim) $9900 \pm 50-26.6----9653-9596$ (4.9\%) 11,602-11,545 (4.9\%)

9546-9480 (4.9\%) 11,495-11,429 (4.9\%)

9463-9257 (85.5\%) 11,412-11,206 (85.5\%)

12DHAIIIG22 Charred residues (outer rim) 10,300 \pm 50 - $30.79 .843 .41 .534 .9104,35-10,316(13.3 \%)$ 12,384-12,265 (13.3\%)

$10,296-9986(76.9 \%)$ 12,245-11,935 (76.9\%)

9938-9884 (5.1\%) 11,887-11,833 (5.1\%)

12DHAIIIG22 Charred residues (inner rim) 10,430 $\pm 50-31.39 .112 .50 .818 .7$ 10,581-10,153 (95.4\%) 12,530-12,102 (95.4\%)

Technological Observations

From the profile of the sherds and the places where the surface layer has chipped, one can observe that this type of pottery was made by mixing homogenously thin plant fibres with clay to make coils and accumulating them to shape the object. The interior and exterior surfaces of the object were then covered with a layer of fine clay. The ridges of the coils are still clearly observable on the surface of the artifacts. According to chemical composition analysis, these earthenware vessels are made from clay with a high iron content, fired at no more than $600{ }^{\circ} \mathrm{C}$ (Liu et al. in prep). The paste is extremely friable and brittle, especially the inner and outer layers, which tend to flake off easily. During the excavation, if the sherds were not left to dry out for a sufficient period before being removed from the ground, they would often crumble.

A small number of vegetable-fibre-tempered sherds were found with a small quantity of crushed shell mixed into the tempering material in features that were slightly later in stratigraphy than phase I, and in some rare cases, contained a small proportion of quartz grains. These sherds are harder than the average vegetablefibretempered pottery sherds. They belong to a later stage within the Houtaomuga phase I pottery.

Function

The fact that vegetable-fibre-tempered sherds with a small quantity of crushed shell mixed into the tempering material were found in features that were slightly later in stratigraphy shows that during the latest stage of phase I, people were already trying 
to modify the tempering material used in making pottery, in order to make it more resistant to fire and shock. They might have found through experimentation that fibre-tempered vessels are easy to manufacture, light and have good resistance to thermal shock, but are 'less advantageous than mineral-tempered pottery in heating effectiveness, abrasion resistance, and drying time' (Rice 1999, p. 27). Research on pottery function led by James Skibo shows how organic temper influences vessel performance in manufacture and use (Skibo et al. 1989). According to this author, organic temper is 'used in early pottery as the absorbent matter that dried out the clay and permitted a vessel to be made in one sitting' (Skibo 2013, p. 6). It also makes a vessel comparatively lighter, which could be a factor in portability (Skibo et al. 1989; Skibo 2013, pp. 40-42). And adding shell powder or sand would make a 'coarsely tempered cooking ware [which] would have greater resistance to thermal shock and mechanical stress' (Skibo 2013, p. 44).

Fig. 2 Comparison between the pottery from Houtaomuga phase I and other sites. 1-8. Changtuozi-3 site (surface collection 4, 2, 3, 1, 15, 16, 7, 5); 9-17. Houtaomuga phase I (zone AIII ditch n.18 :26, pit n.125:1, ditch n.G18:5, ditch n. $18: 21$, pit n.146:2, square 1006 layer :6, square 1006 layer :5, ditch $n$. 18 :19, pit n.H189:10); 18-24. Goncharka-I Site (zone E/4, zone U/10, zone V/6, zone U/1, zone O/12, zone Z/16, zone D’/4-5.3p1); 25-28. Ust'-Karenga-12 Site layer 7. Source: 1-8. Jin et al. (2011, Fig. 5 , p. 5; 18-24). Shewkomud and Yanshina (2012, Fig. 85, p. 157, Fig. 91, p. 162, Fig. 97, p. 167, Fig. 99, p. 170); 25-28. Vetrov (1985, Fig. 1-1 \& 2, p. 126, Fig. 2-1, p. 127, Fig. 3-1, p. 128)

According to some authors, these containers seem well-suited for stone-boiling by semi-sedentary hunter-gatherers (Liu and Chen 2012, p. 66). For example, the containers of the Shangshan Site in Zhejiang are believed to have been used in such a way (Liu 2006). But this cooking method takes constant monitoring and is less effective for simmering; in a ceramic container, the temperature can be controlled and maintained more easily than by indirect heating with hot stones (Skibo 2013, pp. 97, 177-178).

The early examples of pottery excavated from South China, northern China and the Japanese archipelago are all fire-resistant sand-tempered or fibre-tempered pottery, and traces of soot can be observed on some of them. There is no doubt that they had a cooking or boiling function. For example, the early pottery excavated from sites in the Russian Far East, and at the Houtaomuga Site, is all tempered with vegetable fibres or crushed shell, which can produce good fire-resistance. Of course, the environment, the subsistence mode and the type and dimensions of the pottery containers in different regions all have a close relation to the actual function of the pottery. As Anne Underhill points out, pottery containers may have been independently invented in different regions under different conditions and for different functions (Underhill 1997, pp. 115-166; Shelach 2000, p. 378). According to Skibo and Schiffer, the most common reason that people may have adopted pottery is that it can be used to directly heat its contents (Skibo and Schiffer 2008, pp. 37-51; Skibo 2013, p. 12). The question of whether early pottery was created as part of early 'prestige technology', as an instrument of social differentiation (Hayden 1995, pp. 
260-261), or as a 'practical technology' to increase subsistence activities is still being debated (Rice 1999; Jordan and Zvelebil 2009; Zhushchikhovskaya 2012, p. 75).

The crucial question is: what was the motivation for the initial creation of pottery in these various regions? There does not seem to be a single answer; as James Skibo puts it, 'researchers are left to tease out the complex set of social, environmental, and subsistence issues at play in the introduction and use of this important technology' (Skibo 2013, p. 181). Several scholars have advanced hypotheses that address this problem. The current point of view among Japanese scholars (Tsutsumi 2000; Pearson 2006) is that, following the intense climate change of the late Glacial period, the large animals which were the usual prey of the hunters progressively disappeared, and human groups had to rely on resources like river fish and acorns. To be edible, acorns and nuts need to be boiled to get rid of their tannins. Some researchers consider this to be one of the main causes of the appearance of pottery in Japan, as well as in northern and southern China (Liu and Chen 2012, pp. 46-58, 64-68).

However, no remains of acorns used as food have been discovered with the early pottery of the Russian Far East and surrounding regions. Rather, net sinkers have been found at the Gasya and Khummy sites, suggesting fishing practices (Kuzmin 2008 , p. 5). Fish resources are very rich; scholars have pointed out that the appearance of pottery might be linked to the use of fish as a food resource, with ceramic vessels used as storage or to purify fish oil (Medvedev 1995). This is supported by recent lipid residue analysis, alongside carbon and nitrogen stable isotope analysis of charred food residue on 101 samples from 13 sites across the Japanese archipelago (Craig et al. 2013). As for southern China, the dates of the earliest pottery continue to get older, and pre-date rice agriculture (Fu 2012; Wu 2012; MacNeish and Libby 1995; MacNeish et al. 1998). Following the discoveries of large quantities of wild rice and very small quantities of primitive cultivated rice at sites like Yuchanyan in Hunan Province, and Xianrendong and Diaotonghuan in Jiangxi Province, some scholars now think that pottery was originally mainly used to boil rice grains (Zhao and $\mathrm{Wu}$ 2003), or to extract fat and marrow from bones (Cohen 2013). Because of the association of large quantities of fish bones and clam shells with the excavated early pottery in South China, some scholars have also pointed out that 'initially, in South China, what needed to be boiled was not wild rice, plant seeds, or root tubers, but aquatic animals that are difficult to eat and have a rancid smell, such as snails and clams' (Zhou 1994). The large quantity of shells found in the earliest layers of most of the early pottery sites in Lingnan region have shells which are quite complete and do not show traces of opening while raw. This reinforces the hypothesis that early pottery might have been used to cook the shell in boiling water (Fu 2012). In comparison with regions like South China, the Japanese archipelago and the Russian Far East, the location of the Houtaomuga Site, in the valley of the middle and lower course of the Nen River, is a low and humid flat plain, composed of numerous lakes and marshes, and lacking in forest resources. Analysis of pollen samples taken from Houtaomuga (Tang et al. in prep) shows that pollen fossils from 
fungus, which are characteristic of the vegetation of the Tertiary period, gradually decreased, and that the proportion of pollens from herbaceous plants increased during Houtaomuga phase I. At that time, plants from the pteridophyte family (lichens) make up a relatively large proportion of the samples; xylophyta (woody plants) are completely or almost absent. Overall, the landscape was one of pastures and grasslands, with a moist and cold climate. The presence of pollen from polygonaceae (smartweed) shows that there were wetlands in the vicinity of the site (Tang et al. in prep). The surroundings of Houtaomuga and the Song-Nen Plain had a very different landscape than the Amur River Basin, which was covered by birch-larch forests with some broad-leaved trees (Kuzmin 2008).

In comparison to terrestrial mammals, the rich resources of shallow-water fish, shellfish, shrimp and birds (including birds' eggs) are actually easier to obtain, and are also more stable as food resources. Indeed, in the layers and features belonging to phase I of Houtaomuga, remains from aquatic animals were far richer and more numerous than mammal bones, indicating that people mainly relied for their subsistence on aquatic animal resources available in the surroundings of the site. Moreover, in the flotation samples from phase I, we found large quantities of wild grass seeds, which indicates that wild plant seeds were an important food resource for the ancient inhabitants of Houtaomuga. Inside the limited excavated area, no house features have yet been discovered, but pits and ditches connected to human activities and occupation have been identified, as well as one burial. As mentioned earlier, over two thousand pottery sherds have been discovered in this context, most of them in a ditch full of large shells. All the evidence indicates that human activities were not of short-term duration, but that human groups could have already entered a stage of semi-sedentary or seasonally mobile life.

From 2012 to 2015, in the $160 \mathrm{~km} 2$ covered by the yearly systematic regional survey on the south bank of the Xinhuang and Yueliang Lakes, hundreds of sites belonging to various periods of human activity have already been discovered around the Houtaomuga Site, but they include only one new site attributed to Houtaomuga phase I (Liu et al. 2016). This actually suggests that human groups from Houtaomuga could use the aquatic and dry land resources in this area, extending across at least 20,000 ha. Since there is only one other site in the vicinity dating to this period, the residents of Houtaomuga had little competition for resources. We believe that it was the stability and abundance of the food resources, and control over them, that led to a change in mobility patterns or the start of a type of semi-sedentism. The appearance of pottery among seasonally sedentary communities of hunter-gatherers mostly relying on fish and shellfish in rich aquatic environments is claimed all around the world from the period of transition between the Late Paleolithic and the Early Neolithic (Rice 1999; Dolukhanov et al. 2005; Valentin 2010, p. 68; Zhushchikhovskaya 2012, pp. 71-72).

Ethnographic research also shows the importance of storage for hunter-gatherers, especially among fishers and plant-gathering groups living in areas with strong seasonality in resource availability (Testart 1982). 
In order to test the hypothesis of the role of an aquatic-fauna-based subsistence economy in the appearance of pottery at Houtaomuga, during the ${ }_{14} \mathrm{C}$ dating analysis of the pottery of the first phase of Houtaomuga at the University of Tokyo, samples were also subjected to carbon and nitrogen isotope analysis (Table 2). Of a series of 7 samples, only 4 contained carbon and nitrogen, as well as a measurable carbon/ nitrogen ratio. In these samples, the values of carbon isotope $\delta 13 \mathrm{C}$ were all in the $-25.8 \%$ to $-31.3 \%$ range, which coincides with the range of change of $\delta 13 \mathrm{C}$ in the $\mathrm{C} 3$ type plants. On two samples the nitrogen $\delta 15 \mathrm{~N}$ values were basically close to modern rice and modern foxtail millet (Setaria italica); in combination with the Carbon $\delta 13 \mathrm{C}$ value, we can infer that they might have come from C3 type plants.

And these two samples do indeed come from the vegetable fibres used as tempering material and the clay in the paste of the pottery sherds. In the other two samples, the nitrogen $\delta 15 \mathrm{~N}$ isotope value is higher than that for modern rice and modern foxtail millet, showing that these samples contained animal protein, most certainly coming from carnivore animals or freshwater fish. And these last two samples come from carbonized organic material stuck inside and outside the pottery, very probably belonging to food residue (Kunikita et al. in press). The paleopathological analysis of the individual in the burial from Houtaomuga phase I shows stress markers on the teeth, which might indicate stress during the growth of the individual, and the severe tooth-wear can be linked with the consumption of a large quantity of shells containing sandy or silt remains from the lake water (Xiao 2014, pp. 9-21).

So, it seems that the function of the early pottery containers discovered at the Houtaomuga Site fits the model of the emergence of pottery coinciding with an increasing reliance on fishing and exploitation of aquatic resources and environments by postglacial communities of hunter-gatherers (McKenzie 2009, p. 198; Jordan and Zvelebil 2009; Rice 1999; Zhushchikhovskaya 2001; Hommel 2017).

\section{The Background in East Asia}

\section{Previous Early Pottery Discoveries in China}

In China, research into early pottery began in the 1960s. Chinese scholars discovered pottery sherds in South China during excavations at the Qingtang Site in Wengyuan District, Guangdong Province (Guangdong 1961); the Xianrendong Site in Wannian District, Jiangxi Province (Jiangxi 1963; Jiangxi 1976); and the Zengpiyan Site in Guilin City, Guangxi Province (Guangxi et al. 1976) (Fig. 1). These were mostly cave sites. The sherds were discovered in lower stratigraphic levels, and were thick, with a crumbly, sandy fabric - traits which led the excavators to conclude that they were very early.

At the end of the 1970s, successive discoveries of pottery dating from over 10,000 BP in the Japanese archipelago and the Russian Far East prompted Chinese scholars to renew their efforts to look for such remains. In South China, the following sites were successively excavated or re-excavated: Miaoyan, in Guilin, Guangxi Province (Chen 1999); Zengpiyan (Zhongguo et al. 2003); Dayan, in Lingui (Fu et al. 2001); Dingsishan, in Yongning (Zhongguo et al. 1998); Yuchanyan, in Daoxian, Hunan Province (Yuan 2013); Xianrendong, in Wannian District, Jiangxi; Diaotonghuan 
(Beijing et al. 2014); Niulandong in Yingde City (Jin et al. 1998; Yingde

et al. 1999); Shangshan at Pujiang, Zhejiang Province (Zhejiang et al. 2007); and

Shenxiandong, at Lishui, Jiangsu Province (Ge 1990). Early pottery sherds dating from around 10,000 BP were discovered at all of these sites.

Let us briefly present these sites from south to north.

\section{South China}

The Dingsishan Site is located in the Yongning District, in the wet and warm environment of South Guangxi Province, at the top of a triangular limestone (karst) hill of a terrace at the confluence of a tributary of the Yong River and a clear water spring. The surface area of the site is estimated at $5000 \mathrm{~m} 2$. It was surveyed in 1994 and 1996, and a total of $1050 \mathrm{~m} 2$ was excavated between 1997 and 2001.

Four stratigraphic phases have been identified. Only a few sherds and lithic artifacts (microblades and cores) were discovered in the earliest level. These sherds are yellow-grey with a darker core, tempered with quartz grains, and have a crumbly texture. The outer surface of all the sherds presents wide cord marks (over $3 \mathrm{~mm}$ ). The temper was prepared by smashing quartz pieces into grains before adding them to the clay (Zhongguo et al. 1998). The thickness of the sherds is uneven and the

firing temperature seems to have been low. The sherds appear to belong to roundbottomed vessels.

In 1997, 16 tombs (mostly containing flexed burials) were discovered in the second stratigraphic phase, and 133 tombs (also mostly flexed burials) in the third level; more burials were uncovered in subsequent excavations (Tan 2002, 2010). Only pottery, stone, bone and shell implements have been discovered in the fourth phase. The first phase is dated just on $14 \mathrm{C}$ date (on shell) to around 10,000 BP. The second and third phases have been attributed to the Middle Neolithic, around 8000-7000 BP, and the fourth phase to around 6000 BP (Zhongguo et al. 1998). More importantly, the use of the shellfish as both food source and raw material has been analyzed in a study that shows the importance of this type of water resource for the subsistence and crafts at the Dingsishan Site (Lü and Fu 2010). Paleobotanical analysis show that rice phytoliths only appear in the fourth phase (around $6000 \mathrm{BP}$ ) and that the subsistence economy of phase I to III did not rely on agriculture (Zhao et al. 2005b). The Dalongtan (Liyuzui) Site is located at the bottom of the Liyuzui Mountain, in Liuzhou City in north-central Guangxi Province. It is a shell mound of about $200 \mathrm{~m} 2$. It was discovered in 1980 and excavated then $(60 \mathrm{~m} 2)$ and in 2003. Three sets of human remains, stone tools, bone artifacts, a large quantity of animal bones and a few sherds were discovered. The sherds from the earliest level are red or black, with a sandy fabric, and fired at a low temperature. They are relatively thin $(0.2-0.8 \mathrm{~cm})$ and have cord-marked surfaces. They were attributed to the Early Neolithic period by the authors of the report (Liuzhou et al. 1983). Human bones and shell from the earliest level have produced ${ }_{14} \mathrm{C}$ dates between 20000 and 11,000 BP (Liu 2002). Further dating and paleoenvironmental analysis allow us to divide the occupation of the site into three phases: 20,000-15,000 BP; 15,000-12,000 BP; and 10,000-6000 BP. The appearance of pottery occurs during the second phase, 
with $14 \mathrm{C}$ dates around 11,100-10,200 BP (Wu 2012), when subsistence appears to be based primarily on boiled shells (Jiang and Tan 2009).

The Zengpiyan Site is located in a limestone cave on a hill in the south of Guilin City in Guangxi Province. It was discovered in 1965 and excavated in 1973 (Guangxi et al. 1976) and again in 2001 (Zhongguo et al. 2003). This small cave measures around $220 \mathrm{~m} 2$. It yielded flexed and secondary burials, as well as numerous open hearths, with lithic tools, shell artefacts, and numerous animal bones (including possibly-domesticated pig, discussed in Underhill 1997, pp. 135-136). Large quantities of pottery sherds were recovered. Sherds from Zengpiyan are sandtempered, unevenly thick (from 0.3 to $2.6 \mathrm{~cm}$ ), but mostly thin $(0.5$ to $0.7 \mathrm{~cm}$ ) and low-fired. Their surface is red or grey and most of them have cord marked surfaces. The 2003 report dates the site from 12,000 to 7000 BP. This long sequence was subdivided into 5 phases of one thousand years each, which all contain pottery sherds. Geological and sedimentological research into the formation of cave deposits at Zengpiyan shows that this cave was formed during the late Pleistocene. New radiocarbon dates from pottery sheds, animal remains and charcoal, as well as pollen analysis, suggest that the cultural layers were deposited between 12,500 and 7600 $\mathrm{BP}$ (Zhang et al. 2011). The last $14 \mathrm{C}$ dates measured for the final report give a range of 14,000-9500 BP for the use of pottery (Zhongguo et al. 2003; Wu 2012). The paleobotanical studies did not find any evidence for agricultural practices, but a large quantity of wild mammals, and more importantly of shells and gastropods, have been discovered in the cave (Zhang 1989), highlighting the importance of this type of food product in the subsistence economy of the period. The numerous traces of fires in the cave could indicate the practice of cooking food.

The Dayan Site, also located in the Guilin region, in Lingui District, is composed of two caves (A, $3000 \mathrm{~m} 2$ and B, $15 \mathrm{~m} 2$ ); $72 \mathrm{~m} 2$, was excavated between 2000 and 2001. Ten burials and ten hearths were recovered, along with sherds, stone, bone and shell artifacts. The stratigraphic sequence was divided into six phases. Pottery sherds appear in the second phase, among a large shell deposit, along with two flexed burials, and lithic and bone artifacts. It has been dated from the transition period between the end of the Paleolithic and the very beginning of the Neolithic, so far without further precision (Fu et al. 2001).

The Miaoyan Cave Site is located south of Guilin City. It was discovered in 1965 and excavated in 1988. Two flexed burials, traces of fire, faunal remains including large quantities of shells, stone tools, bone and shell artifacts, as well as pottery sherds were discovered in this cave (Chen 1999). The sherds are grey-brown, sand-tempered, thick, crumbly and fired at low temperature. A series of ${ }_{14} \mathrm{C}$ samples dates the cave deposit at 22,000 and 12,000 BP. The date of the earliest pottery at the Miaoyan Site is bracketed between 21,600 and 16,400 BP; a sample from the fifth layer had a $14 \mathrm{C}$ date of c. 18,000 BP; and two samples of organic residue on the sherds were dated c. 15,600-15,500 BP (Wu 2012). Thus far, no evidence for domesticated plants or animals has been discovered, and the subsistence economy seems to have mainly been based on water resources (Jiang 2006).

Yuchanyan Cave is located in Daoxian District, in the far south of Hunan 
Province. The site was discovered in 1988 and excavated in 1993 and 1995, and by a Sino-American team in 2004-2005, yielding remains of fauna, shells, plants (including only five rice grains, discussed in Cohen 2013, p. 67), stone tools, bone and shell artifacts and pottery sherds, as well as traces of fire. The sherds are very thick $(2 \mathrm{~cm})$, and fired at low temperature $\left(400-500{ }^{\circ} \mathrm{C}\right)$. The paste is tempered with crushed quartz and water-polished pebbles. A reconstructed $f u$ caldron is conical in shape with a pointed round base; it measures $29 \mathrm{~cm}$ in height and $31 \mathrm{~cm}$ in diameter. The interior and exterior are impressed with cord marks. Pottery sherds from the site have been securely dated to as early as $18,300-17,500 \mathrm{BP}$ and up to 15,430 BP (Boaretto et al. 2009; Wu et al. 2012a). This cave site has been interpreted as a foragers' camp (Yuan 2013), the west side of the cave being where humans most frequently gathered (Gu and Yuan 2006). The dominance of birds, deer and fish in the faunal assemblage shows a dietary expansion among the hunter-gatherers living here (Yuan 2013; Cohen 2013).

Niulandong Cave is located at the top of a limestone peak in the hilly region of the Yingde District in the north of Guangdong Province. The cave measures around $400 \mathrm{~m} 2$. The site was discovered in 1983 and partially excavated in $1996(50 \mathrm{~m} 2)$. Most of the finds were flaked stone tools, associated with a small quantity of ground stone artifacts, pottery sherds and faunal remains. The cultural layers were divided into three phases. Pottery sherds appear only in phase II. The five sherds are tempered with sand, grey in colour, and of uneven thickness $(0.6-1.1 \mathrm{~cm})$. Only one of them has cord marks. The report attributes these remains to the Mesolithic period

(Jin et al. 1998; Jin 2011), without more precise dates.

The group of cave sites around Qingtang is located between two rivers in the Wengyuan District in northern Guangdong Province. It was discovered in 1959 and excavated in 1961. Most of these caves yielded a large quantity of lithic tools and a few sherds. These are tempered with sand and crushed stone; thin; red, grey or black in colour; and decorated with cord marks, chevrons, basketry impressions and gridlike patterns (Guangdong 1961). Analysis shows that this pottery had been fired at around $680^{\circ} \mathrm{C}$ (Peng 1981).

Qihedong Cave is located in Zhangping City in Fujian, next to a stream at the foot of a limestone hill. It was discovered in 2008 and excavated over three seasons between 2009 and 2011 (total of $96 \mathrm{~m} 2$ ). The excavation yielded activity floors, houses, and pit hearths; human and faunal remains including a large quantity of shells; stone and bone artifacts and pottery sherds. These remains have been dated to $17,000-7000 \mathrm{BP}$, and can be divided into three broad phases. The earliest sherds were recovered from the second phase, and are dated to between 12,000 and 10,000 BP. These sherds (over 200) are reddish brown or brown, mainly tempered with sand, thick, and fired at a low temperature. Most have no decoration; a small proportion have cord marks and impressed dots. No shape could be reconstructed, but the rims seem to all belong to guan jars with a diameter ranging between 15 and $30 \mathrm{~cm}$ (Fujian et al. 2013; Fan and Wang 2012).

Xianrendong and Diaotonghuan are the most famous of the early pottery sites in China. These two caves are located $800 \mathrm{~m}$ apart in the northeast of Jiangxi Province, 
about $100 \mathrm{~km}$ south of the Yangzi River, in Wannian District. Xianrendong Cave was discovered and first excavated in 1962. This limestone cave fill mainly consists of dense shell and animal deposits across an area of around $100 \mathrm{~m} 2$. During the first excavation, hearths, human remains and lithic, bone and shell artefacts were recovered, along with pottery sherds. These remains were divided into two cultural levels. The sherds from the first level are coarse, tempered with unevenly mixed quartz grains, fired at low temperature, crumbly in texture, and red at the surface with a brown core. They are also of uneven thickness $(0.7-1.4 \mathrm{~cm})$. All of the sherds show thin or thick cord marks. One guan jar has been restored: it has a round bottom, straight walls and a slightly everted rim (Jiangxi sheng wenwu guanli weiyuanhui 1963).

The site was excavated again in 1964 (Jiangxi 1964; Jiangxi 1976), in order to clarify the stratigraphy; 198 sherds similar to those described in the report of the first season were uncovered from the lower levels. Further excavations from 1993 to 2000 , and by a Sino-American team in 2009, set out to clarify the stratigraphy and chronology of the site. Analysis of the stone tool assemblage and the faunal remains led researchers to consider Diaotonghuan Cave as a temporary camp and butchery site for the inhabitants of the Xianrendong (Zhao 1998). Twenty-two pottery sherds and two soil samples from Xianrendong were analyzed to determine their chemical composition and microstructure; they were also dated through thermoluminescence. The main raw material used to make pottery was local red clay, tempered with quartz and feldspar, which was fired at between 740 and $840{ }^{\circ} \mathrm{C}$. The thermoluminescence dates are later than expected: around 10,000 BP (Wu et al. 2005). However, a large series of carefully chosen radiocarbon samples was obtained in 2009 under the best possible conditions and a new chronology was established. The upper level is now attributed to 14,000-9000 BP and the lower level to 20,000-15,000 BP (Wu et al. 2012a; Cohen 2013, pp. 61-62).

The Shangshan Site is located in Pujiang District, in central north Zhejiang Province, on the south bank of a tributary of the Pu River, at the top of a hill at the centre of a small basin in a low mountain range. The site measures over 20,000 m2. It was discovered in 2000 and excavated three times - in 2011, 2004 and 2005-2006exposing a total of $1800 \mathrm{~m} 2$. Pits, houses, lithic tools and pottery sherds were discovered. The remains were divided into two phases. The sherds belonging to the early phase were tempered with vegetable fibres, which upon further analysis were identified as rice grains, husks and leaves (Zheng and Jiang 2007). These sherds were fired at a low temperature (around $800{ }^{\circ} \mathrm{C}$ ) and have a light yellow colour; they are mostly very thick (c. $2 \mathrm{~cm}$ ). Most of the shapes had a flat base, while a small proportion had a round or circular bottom. Most of the shapes are basins, cups and jars. Most of the sherds were undecorated, while some had cord marks or other impressed patterns. The remains of the early phase have been dated by a series of ${ }_{14} \mathrm{C}$ samples to between 10,000 and $8500 \mathrm{BP}$. This site shows evidence for the beginning of rice agriculture coupled with collecting and hunting in a mixed subsistence model (Zhejiang et al. 2007).

Shenxiandong Cave is located in the southeast of the Jiangsu Province, south of 
Nanjing. This limestone cave opens on the northwest slope of the Huifeng Mountain. The site was discovered in 1975 and excavated in 1977 and 1978. The sherds are brown or red, fired at low temperature and have been dated to before 10,000 BP (Ge 1990). One charcoal sample was dated by $14 \mathrm{C}$ to around $12,600 \mathrm{BP}$ and another one belonging to the same context as the early sherds to c. 10,800 BP (Wu 2012). Uranium/thorium ratio analysis shows that the cave's deposit was formed during the late Pleistocene and that the human remains date from the end of the late Pleistocene or the very beginning of the early Holocene (Wang et al. 2006).

In South China, the surface of early pottery often presents patterns of unevenly thick cord marks or woven patterns (Beijing 2014; Yuan 2000, 2013). The inner surface of some artifacts also presents cord marks. The majority of specialists think these are the results of paddling impressions made with an instrument wound with cord or some kind of support (Zhu 1999). However, Wang Xiaoqing has pointed out that these impressions could be the result of the use of a mould made of a woven artifact to shape these early vessels (Wang 1995). According to the data from the report on the Xianrendong Site, the most common technique used to shape these early vessels was the accumulation of clay strips. The pottery with applied cord marks or woven patterns displays traces interpreted as having been left by fingers pinching and pressing at the joints on the top and bottom of the clay strips used during the shaping of the object; these clearly cannot have been made while using an inner or outer mould. Only sherds excavated from the earliest stratigraphic units in the western zone of the cave (3C1B) present traces of stripes resembling basketry patterns. The point at which the clay strips connect is shaped like an inclined plane, without traces of finger pressure above or below, so it appears that the vessel actually was shaped with a mould. From the perspective of technological development, the production of the earliest large pottery vessels could not practically have been achieved without the help of a woven artifact used as a support during the shaping process.

The Debate on the Chronology of the South China Sites Research and debates on these southern Chinese sites have been mainly focused on chronology. The very early dates of Xianrendong, Zengpiyan and Yuchanyan present a considerable disruption to the accepted cultural framework of Chinese archaeology, and were initially rejected by the academic community. The long process of acceptance began in the 1970s, when shells discovered with pottery sherds at the Xianrendong and Zengpiyan sites were dated by $14 \mathrm{C}$ to before $10,000 \mathrm{BP}$. The excavators believed that this period should belong the Early Neolithic. However, ${ }_{14} \mathrm{C}$ dates for the animal bones proved to be much later than the shells. In 1977, Prof. Xia Nai-at that time director of the Institute of Archaeology in the Chinese Academy of Sciences - published an article stating that he suspected that the shells from these two sites had been contaminated by the limestone environment in which they were buried and that their dates may have been overestimated as a result (Xia 1977). His doubt was echoed by An Zhimin - at that time vice-director of the Institute of Archaeology in the Chinese Academy of Sciences and dean of the Archaeology 
Department—who, in an article on radiocarbon dates from early Neolithic sites in South China (An 1989), vehemently rejects all the previous $14 \mathrm{C}$ dates in the region as erroneous. Mentioning 'regional anomalies', 'contradictions of stratigraphic horizons with ${ }_{14} \mathrm{C}$ data', and 'inconsistency with levels of cultural development', he simply could not believe that pottery appeared so early in China.

In response to these views, Yan Wenming, professor at Beijing University, stated in 1987 that the southern sites around Xianrendong could be as early as 9500-8000 BP and the earliest pottery around 10,000 BP (Yan 1987). A few years later, Yu Weichao, by then director of China's National History Museum, acknowledging the constant progress in radiocarbon dating methods, also put the first pottery at 10,000 BP (Yu 1991).

The sceptical stance adopted by Xia Nai and An Zhimin toward the $14 \mathrm{C}$ dating of the early pottery sites has had a profound impact (Sun 2002). For example, the article by Xia Nai was still quoted by Peng Shifan in 1981 in his article about the early Neolithic cultures in South China, where he put the founding of Xianrendong at 'not earlier than $8000 \mathrm{BP}$ ' and attributed the Zengpiyan remains to the 'Middle Neolithic' (Peng 1981). In a synthetic article on the chronology of the late Pleistocene/ early Holocene in the Lingnan region, Jiao Tianlong (1994) also echoes An Zhimin's doubts and does not use the early dates of the cave sites of this region. In 1997, one shell sample from the Dingsishan Site was dated by $14 \mathrm{C}$ to around $10,000 \mathrm{BP}$, but the authors of the report doubt these results and consider the date too early (Zhongguo et al. 1998). The same pattern is repeated in a recent article by $\mathrm{Fu}$ Xianguo (2012), who still does not use the early dates published for Yuchanyan and Xianrendong.

In recent years, due in large part to the systematic sampling carried out by the Sino-American archaeological teams at Xianrendong, Diaotonghuan and Yuchanyan, the date of the earliest pottery production in South China was ultimately fixed around 20,000-19,000 BP at Xianrendong (Wu et al. 2012b) and 18,300-15,430 BP at Yuchanyan (Boaretto et al. 2009). Despite some recent controversies (Kuzmin 2006), these finds are now mostly accepted as the earliest known pottery remains anywhere in the world (Wu 2012; Cohen 2013).

The difficulty of radiocarbon dating and the possibility of sample choice influencing the date of shell and bone in the Lingnan region have recently been the subject of a new study, showing the progress made in taphonomy in karstic environments, in sample selection and ${ }_{14} \mathrm{C}$ methods (Chen 2015). Paleoclimate and botanical study in the Guilin region show that early pottery from the northern Lingnan region might have been used to cook plants from the taro (Colocasia esculenta) family (Lü 2008). A spatial distribution analysis of all the sites dated between 20,000 and 10,000 BP in the Lingnan region, including a focus on stone and bone tool assemblages, interestingly shows that pottery sherds appear only in the northern Lingnan region, along with stone and bone shovel-shaped tools, which might shed new light on the human activities linked to the invention of pottery in the very south of China (Chen 2016).

\section{North China}


In North China, early pottery sherds were successively discovered in Hebei Province at the sites of Nanzhuangtou (Baoding et al. 1992; Hebei 2010); Yujiagou in Yangyuan (Mei and Xie 2002); Donghulin in Mentougou, just outside Beijing (Donghulin 2003; Zhao et al. 2003, 2005; Beijing et al. 2006); Zhuannian in Huairou (Yu et al. 1998; Yu 2002); and, in Henan Province, at the site of Lijiagou in Xinmi (Zhengzhou et al. 2013; Beijing et al. 2013; Wang 2014b, pp. 16-19). There are comparatively fewer sites discovered in North China, and the ${ }_{14} \mathrm{C}$ dates associated with the early pottery sherds all cluster around $10,000 \mathrm{BP}$, all clearly a few millennia after the appearance of the earliest pottery in South China.

The Lijiagou Site is located in Xinmi City, in the Middle Yellow River Valley, in the centre of Henan Province, next to a river in the hilly region at the eastern foot of the Song Mountains. It is so far the only early pottery site found in the Yellow River Valley. It was discovered in 2004 and excavated in 2009 and 2010 (100 m2). Only two sherds were discovered in the level dated from 10,500 to $10,300 \mathrm{BP}$, along with an activity floor, stone artifacts including a large quantity of microblades and animal bones. These sherds are grey-black to grey-brown, tempered with large grains of calcite and limestone, fired at a low temperature, and present no decoration. Over two hundred sherds have been discovered in the level dated 10,000-9000 BP. They are grey-yellow to red-brown, tempered with sand, and harder and fired at a higher temperature than the ones from the lower level. They are fully decorated with cord marks and carved patterns (Beijing and Zhengzhou 2011; Zhengzhou and Beijing 2011). The abundance of ground stone tools discovered at Lijiagou led researchers to think that this site shows some of the earliest evidence of millet agriculture in North China (Wang 2013), but further paleobotanical studies will be necessary to verify this hypothesis. The abundance of deer in the faunal assemblage indicates that this large mammal contributed to the diet of the inhabitants of Lijiagou from 10,500 to $9000 \mathrm{BP}$. The analysis of the stone implements and faunal remains led Wang Youping to conclude that this was a seasonal camp for semi-sedentary groups

(Wang 2014b, pp. 16-19).

The Nanzhuangtou Site is located in Xushui District, in central Hebei, south of Beijing, in a limestone area at the eastern foot of the Taihang Mountains, next to the Ping River. It was discovered in 1986. During 1986, 1987 and 1997, over 300 m2 were excavated, yielding ditches; pits; traces of fire; stone, bone and horn artifacts; numerous shells; large quantities of animal bones, including remains of domesticated dog; as well as over twenty pottery sherds (Baoding et al. 1992). Millet starches were also recovered. The sherds are red to brown, crumbly, tempered with sand or mica, quite thick $(0.8-1 \mathrm{~cm})$ and fired at a low temperature $\left(550-900{ }^{\circ} \mathrm{C}\right)$. They are sometimes decorated with comb-dot patterns and added cordons. Formally, the sherds derive from flat-bottomed guan jars, and show traces of heating. Paleoenvironmental studies show that at the time of its occupation the site was surrounded by marshes and lakes. The subsistence economy was based on fishing and hunting (mainly deer) (Hebei et al. 2010).

The Donghulin Site is located in the west of Beijing region, in Mentougou District, on a tertiary terrace on the north bank of the Qingshui River. It was discovered 
in 1966, but only excavated in 2001, 2003 and 2005. The site yielded two pit burials (one of them a flexed burial surrounded by perforated shells); pits; hearths; stone knapped tools, microblades and ground stone tools; bone and shell artifacts; animal and plant remains; and more than sixty pottery sherds. The sherds are red-brown or grey-brown, fired at low temperature $\left(450-550^{\circ} \mathrm{C}\right)$, tempered with mostly large grains of sand, with a small proportion tempered with fine sand. Some have added cordons or impressed patterns. A series of over twenty carbon samples were dated from 11,000 to $9000 \mathrm{BP}$. The authors of the report interpret the presence of grinding stones - along with evidence of millet and acorn-processing and domestic mammals -, as remains of the transition period from a hunter-gatherer economy to agricultural and animal husbandry practices (Beijing et al. 2006).

The Yujiagou Site is located in Yangyuan District in northwest Hebei in the Nihewan Basin - a region famous for its Paleolithic sites — on the bank of the Senggan River, in the cold and arid grasslands northwest of the Taihang Mountains. It was excavated between 1995 and 1998 (roughly 120 m2). A deep deposit (over $7 \mathrm{~m}$ ) yielded a large quantity of microblades, bone artifacts, a lot of animal remains (mainly shells and birds), and pottery sherds. The sherds are red-brown to yellowbrown, tempered with mica, quartz grains or crushed shell, and quite thick ( 0.7 to $1.1 \mathrm{~cm}$ ). They were fired at low temperature, and the rarely-recognized shapes have a flat bottom. The lower level has been identified as a 'microlithic culture' and dated from 14,000 to $8000 \mathrm{BP}$. One pottery sherd has been dated around 11,700 BP (Mei and Xie 2002).

The Zhuannian Site is located in Huairou City, in the north Beijing region, on a secondary terrace on the western bank of the Bai River. The site measures around $5000 \mathrm{~m} 2$. It was excavated in 1992, 1995 and 1996 (on 500 m2), yielding a large quantity of stone tools, including microblades and grinding tools, and a small quantity of animal bones and pottery sherds (around seventy pieces). The sherds are mainly brown, tempered with quartz grains, unevenly fired at low temperature, crumbly and thick $(0.7-1.1 \mathrm{~cm})$. All the recognizable pieces show the presence of flat-bottom containers. Some sherds are decorated with added cordons. These remains have been dated around 10,000 BP (Yu et al. 1998; Yu 2002). Prior to the excavations at Houtaomuga, Zhuannian was the northernmost early pottery site in China.

Because of the later dates, early pottery sites in North China have not received the same amount of attention as their southern counterparts. In a table synthesizing the main characteristics of the early pottery sites previously discovered in China (Table 3), we can see that most of the South China sites are cave sites, but so far no cave site in North China has yielded early pottery sherds. Moreover, most of the southern Chinese cave sites also produced human remains, which are quite rare in the North China sites. Most of the early pottery discovered in China so far is tempered with mineral material (sand, crushed quartz, feldspar, mica, calcite, etc.), and only the Shangshan Site in Zhejiang suggests the addition of plant fibres (rice husks and leaves) as tempering material in the clay. The earliest reliable dates are found in South China, with Xianrendong around 20,000-19,000 
BP (Wu et al. 2012a, b), Yuchanyan around 18,300-15,430 BP (Boaretto et al. 2009), and Miaoyan around 21,600-16,400 BP (Wu 2012). The number of sites is still very low. Often the dates are given without specifying whether or not they are calibrated, and if they are, what they are calibrated on often remains unclear, which greatly limits the research. The broadest problem remains that data are still incomplete for these early pottery sites, but further discoveries and analysis will surely clarify this picture.

At this point, the main research questions revolve around the subsistence mode, which is often interpreted as a transition from hunting-gathering to agriculture and animal husbandry, without much further precision. However, previous researchers have already noted that in 'most regions of east Asia where early ceramics have been found, such as Japan, the Amur, and South China, agriculture developed late. This may suggest that the association between ceramics and the exploitation of cereals is not very strong' (Shelach 2000, p. 378). In his rich synthetic article on the spread of early pottery in East Asia, analysing large trends at a macroscale, David Cohen observes that the North China sites show the appearance of microblades and that the spread of this technology 'could relate to broad-ranging information exchange networks and interactions among mobile, small-sized bands of hunter-gatherers' (Cohen 2013, p. 68).

David Cohen also analyses the correlation between the appearance of pottery in China and other East Asian countries and the climate change processes occurring during the Pleistocene-Holocene transition (Cohen 2013). He observes that all these North China pottery sites 'appear late compared to South China, Japan and the Russian Far East, and they might represent hunter-gatherers retreating to more favourable habitats during the Younger Dryas', and that these sites indicate a 'reduction in mobility and the establishment of semi-sedentary practices' (Cohen 2013, p. 70). His broad review of the published data highlighted the spatial gap existing so far between the North Chinese and the Russian sites, as did the previous work of Kuzmin and many Japanese researchers (Jordan and Zvelebil 2009). New discoveries at the Houtaomuga Site in the heart of the northeast China Plain can now begin to fill this major gap in the distribution of early pottery.

Table 3 Main characteristics of the early pottery sites discovered so far in China (from south to north) (question marks indicate unclear data)

Site name Province Cave site Human

remains

Hearths or

traces of

fire

Pits Temper Bottom

shape

Microblades Ground

stone

tools 
Shells Domestic

plant

remains

Dates for early

pottery (c. BP)

Dingsishan Guangxi Quartz

grains

$\checkmark \checkmark 10,000$

Dalongtan Guangxi $\checkmark$ Sand $\checkmark \checkmark \checkmark \checkmark$ 11,100-10,200

Zengpiyan Guangxi $\checkmark \checkmark \checkmark$ Sand $\checkmark \checkmark \checkmark$ 14,000-9500

Dayan Guangxi $\checkmark \checkmark \checkmark$ ?

Miaoyan Guangxi $\checkmark \checkmark \checkmark$ Sand $\checkmark$ 21,600-16,400

Yuchanyan Hunan $\checkmark \checkmark \checkmark$ Quartz and

pebbles

Pointed

round

$\checkmark \checkmark(5$ rice

grains)

$18,300-175,00$

to 15,430

Niulandong Guangdong $\checkmark$ Sand $\checkmark \checkmark$ ?

Qingtang Guangdong $\checkmark \checkmark \checkmark$ Sand and

crushed

stone

$\checkmark ?$

Qihedong Fujian $\checkmark \checkmark \checkmark$ Sand $\checkmark$ 12,000-10,000

Xianrendong

and Diaotonghuan

Jiangxi $\checkmark \checkmark \checkmark \checkmark$ Quartz and

feldspar

Round $\checkmark \checkmark$ 20,000-15,000

Shangshan Zhejiang $\checkmark$ Vegetable

fibres (rice

husks and

leaves)

Flat $\checkmark \checkmark \checkmark$ (rice) $10,000-8500$

Shenxiandong

Jiangsu $\checkmark$ ? 10,800

Lijiagou Henan Calcite and

limestone

$\checkmark \checkmark 10,500-10,300$

Nanzhuangtou

Hebei $\checkmark \checkmark \checkmark$ Sand or mica Flat $\checkmark \checkmark \checkmark$ (millet) 11,070-8890

Site name Province Cave site Human 


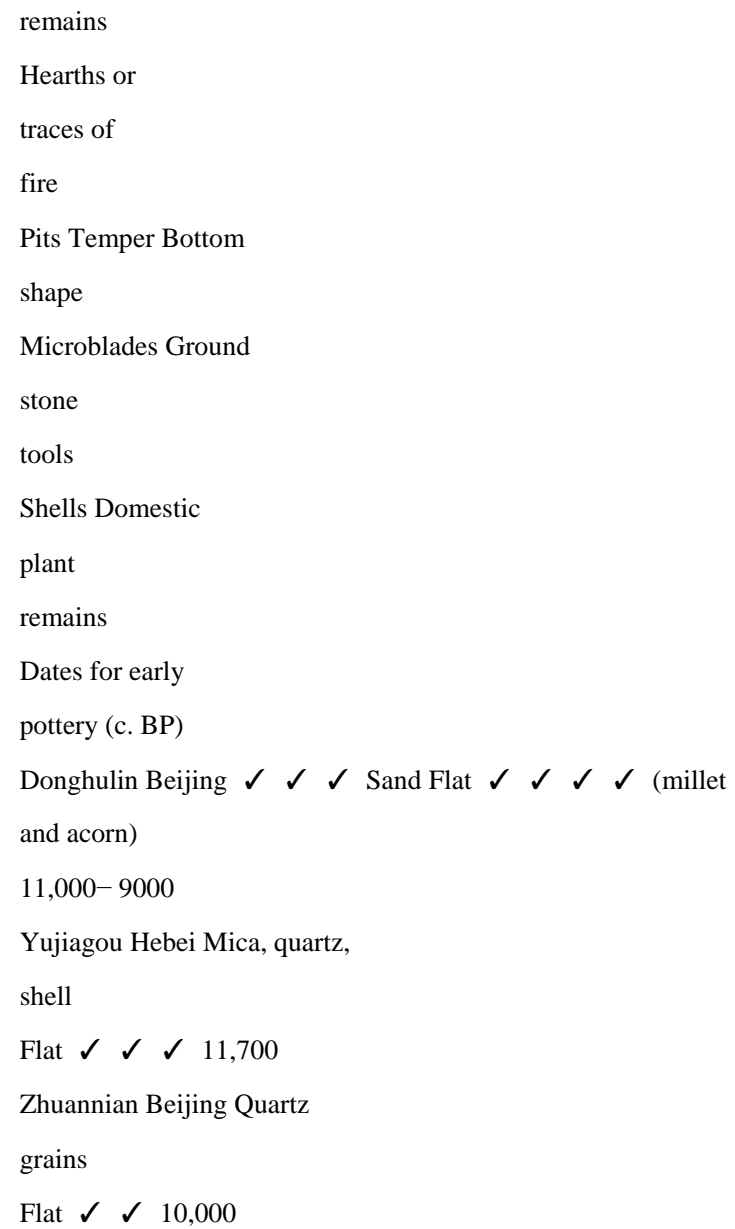

From a macroscopic comparative point of view, the pottery remains from Houtaomuga phase I show general characteristics of early pottery in China - that is to say: use of local common clay; thick and abundant tempering material; handmade, thick walls; loose crumbly paste; and low firing temperature (Zhao and Wu 2000) — but they also show distinct regional characteristics.

\section{Northeast China}

The remains from Houtaomuga phase I pre-date the Shuangta phase I, dated from around 10,000 BP (Jilin 2013), which represented the earliest pottery remains previously known in northeast China. Houtaomuga phase I also pre-dates by three to four millennia the dates from the Xinglongwa culture sites (c. 6200-5400 BC), which have yielded the earliest evidence for 'large-scale' ceramic production and domesticated millet associated with year-round sedentary settlement in northeast China (Shelach 2000; Shelach and Teng 2013), long before the first evidence for millet agriculture in southern Primorye (c. 4800-4600 BP) (Kuzmin 2008, p. 6).

Recent discoveries shed new light on this region. The closest comparative material identified so far can be found in the Nen River Valley, north and west of the Houtaomuga Site (Fig. 3). For example, there are similarities between the pottery of Houtaomuga phase I and sherds that we collected on the surface of the Changtuozi-3 Site in the Tongyu district in 2007, as well as with sherds attributed to the so-called 
Changtuozi type A in published reports (Zhao et al. 2010; Jin et al. 2011). The pottery from the Changtuozi Site contains a relatively small quantity of vegetable fibres added to the clay — most of the pottery is tempered with crushed shell—and a small proportion with uneven grains of quartz. Vessels from Changtuozi are on average $0.5-0.9 \mathrm{~cm}$ thick and have unevenly thick walls, which are usually thinner and less uniform than the ones from Houtaomuga phase I. The surface of the pottery is mostly yellow-grey, and the core of the paste is of a grey-black colour. The paste of Changtuozi pottery has been fired at a higher temperature than that of Houtaomuga I pottery. The mixed temper and hardness of the sherds lead us to think that the Changtuozi pottery is slightly later than the Houtaomuga phase I pottery.

Fig. 3 Map showing the location of early pottery sites around Houtaomuga

The decoration, including short parallel lines, thin lines and parallel oblique line patterns impressed with a flaked-shaped toothed tool, is similar to the Houtaomuga phase I pottery. In the Changtuozi pottery decoration, new motifs appear, such as impressed parallel dots (where the pits are rectangular or fingernail-shaped), and the proportion of reverse round-shape patterns increases; but the comb-tooth chevron patterns, the comb-tooth short arc lines and the comb-tooth zigzags disappear. The orientation of the patterns also becomes more regular (Fig. 2-1 to 8; Jin et al. 2011). Therefore, according to our experience of the general evolution of pottery technology in other parts of Northeast Asia, we can deduce that the remains belonging to Changtuozi type A are slightly later than the remains from Houtaomuga phase I. So far, due to the lack of scientifically excavated material belonging to Changtuozi type A, the assemblage of the pottery artifacts remains unknown, and it is unclear whether these remains belong to a different archaeological culture than the ones from Houtaomuga phase I, or to a different stage of the same culture. We must await future excavations and survey to answer this question; for the time being, we can regard them as two successive cultural types with temporal continuity. By looking at the pottery collected during the Third National Survey of Cultural Relics in the northern neighbouring area of Zhenlai District (unpublished data), we discovered that sherds tempered with vegetable fibres and bearing comb-tooth decoration patterns have been collected at several sites. One of the sherds collected at the Hubutai Site was made of clay tempered with vegetable fibres, and its paste, colour and low firing temperature make it extremely similar to the pottery of Houtaomuga phase I. However, it bears vertical cord marks on its surface, and the traces of this pattern were quite unclear. Another sherd, collected at the Xishagang Site, was decorated with short comb-tooth lines; its paste contained a small proportion of disordered vegetable fibres as tempering material; and its style is very similar to the pottery of Changtuozi type A. This phenomenon could be described, as Hommel (2017) suggests, as 'pottery [...] transmitted directly between neighbouring communities, retaining similar technological styles'. Thus, it can be seen that, even though these sites all lack excavated materials and reliable dates for now, there seems to be a tradition of early pottery developing around Houtaomuga, in the Middle and 
Lower Nen River Valley (Fig. 3).

Japan

Since the 1960s, there have been many discoveries of pottery from the initial stage of the Jomon culture (c. 16,000-14,000 BP) in the Japanese archipelago.

Most of these vessels have a round or pointed bottom (for example, the ones from Odaiyamamoto, Tsukimino-Kamino, Hanamiyama, Fukui Cave, etc.: see Kajiwara and Kononenko 1997; Fig. 1); and only extremely few specimens have a nearly flat bottom. The shapes and decoration of these early pottery vessels resemble those of basketry, animal-skin bags, and containers made of tree bark. Kobayashi Tatsuo has therefore claimed that Japan's earliest ceramics were created in imitation of containers made from these other materials, and named the period when early pottery usually imitated woven materials 'the Age of Image' (Kobayashi 1983). This raises the question of whether it was actually that easy to use clay to directly imitate the appearance of, for instance, basketry and tree-bark containers. The flat bottoms of Houtaomuga appear to contradict this theory; the implications are discussed below.

\section{The Russian Far East}

Houtaomuga pottery shares many of its defining features with pottery from other archaeological cultures. This section will compare the ceramics to those discovered in the Russian Far East, east of Lake Baikal (Krasnaya Gorka and Ust'-Karenga), and mainly in the extreme Far East (Osipovka, Gromatuha) (Fig. 1), clarifying the existing similarities and differences between these productions in the paste, the shaping techniques and the decoration.

So far, important sites from the Ust'-Karenga culture east of Baikal, as well as the Gromatuha culture in the Amur River Valley and the Osipovka culture, have all been considered as yielding evidence for pottery tempered with vegetable fibre (Zhushchikhovskaya 1997), though recent analyses suggest that the vegetal 'temper' seen in pottery from the Ust'-Karenga Site, around 11,200 BP, is of natural origin (Hommel et al. 2017). The fibre-tempered pottery remains from the early stages of the three above-mentioned cultures and the ones from Houtaomuga phase I date to similar periods. Among them, the earliest ${ }_{14} \mathrm{C}$ dates are from the Osipovka culture (16,000-14,000 BP) (Kuzmin and Vetrov 2007; Shewkomud et al. 2009) and the Ust'-Karenga culture (14,150-12,450 BP) (Vetrov and Hommel 2017), somewhat earlier than the remains from Houtaomuga phase I. Charred residue on pottery from the Krasnaya Gorka Site in Buryatia obtained a date around 8345 cal. BP, substantially younger than the pottery from the Ust'-Karenga Site (around 11,200 cal. BP) (Hartz et al. 2012, p. 1043), but the latest dates from this site are consistent with Ust'-Karenga. This type of vegetable-fibre-tempered pottery can be found in Russian and Korean sites dating to 10,000 BP (Tsydenova and Piezonka 2015; Yanshina 2014; Fukuda 2014; Zhushchikhovskaya 1997, 2012; Kang and O 2003, pp. 16-43; Kang 2006). Adding vegetable fibre as tempering material in earthenware paste is apparently a technological tradition that spread extensively over a long period of time in Northeast Asia. 
At the Goncharka-I Site (Shewkomud and Yanshina 2012), the vegetable fibres added as tempering material in the clay of early pottery mostly have a disorderly distribution, and are less concentrated and neatly ordered than the ones in the paste of the Houtaomuga phase I pottery (Fig. 4-1). The analysis of the vegetable fibres added as tempering material in the clay of pottery from the Khummy Site in the Lower Amur River Valley shows that they belong to the Cyperaceae family (Zhushchikhovskaya 1997). The preliminary observations of the vegetable fibres included as tempering material in the clay of early pottery from Houtaomuga phase I indicate that they might belong to plants of the Gramineae family growing around the site.

Fig. 4 Vegetal fibres used as tempering material in the clay of the pottery of Goncharka-I site and Houtaomuga site. 1. Goncharka-I Site zone D’/5; $2 \& 3$. Houtaomuga Site zone AIII ditch 18 . Source: 1. Shewkomud and Yanshina (2012, Fig. 87-2, p. 159)

The pottery excavated from sites which are earlier than the Houtaomuga phase I remains, such as Gasya and Khummy, all have vegetable fibre added as tempering material in their paste, but they also all have temper made of mineral grains of different sizes and belonging to different lithic materials (Zhushchikhovskaya 1997). The inconsistency of the tempering material can also be considered as an indication of very early production. Furthermore, the pottery of Houtaomuga phase I only has temper made of fibres from stems of plants of the Gramineae family, and was shaped by accumulation of clay circles or coils, whose surfaces were coated with fine clay, which made the pottery walls quite thick. At a slightly later stage, attempts to mix crushed shell and quartz grains in the temper appeared. This shows that, from the perspective of human control, the pottery from Houtaomuga phase I is a little more advanced than that from the Gasya and Khummy sites. Moreover, even if the decoration on the outer surface of the pottery of Houtaomuga phase I still resembles the style of woven basketry, there is no discernible trace of moulds on the smoothed inner surfaces of these objects. The Osipovka culture reveals another possible explanation for the initial appearance of early pottery (Zhushchikhovskaya 1997). The vessels excavated from the lower levels of the Gasya Site are the earliest pottery containers known so far in the Russian Far East. One nearly complete vessel, with a round shape and a flat bottom, has an outer surface totally covered with vertical fine grooves (Fig. 5-1). Previously, Derevyanko and Medvedev thought that such traces were obtained by scraping the surface of the pottery with a rough instrument bearing teeth, such as a shell (Derevyanko and Medvedev 1996). But Zhushchikhovskaya noticed that these impressions more closely resembled the impressions of a basket. Through meticulous observation of the sherds from the Khummy Site, she discovered that even if the traces on the inner surface of the pottery were made by a wooden instrument leaving parallel long and narrow traces, the criss-crossed or netted impressions on the surface revealed the shaping process of the pottery. These basket-shaped containers were very probably made using a mould or in a woven artifact. She also discovered that, 
on the sherds from the Ustinovka-3 Site, there were no traces of coil winding or coil connections, but on the interlocking parts of the pottery walls there were often traces of application of two distinct layers of clay. This very probably indicates that a moulding technique was used in shaping the object.

Meanwhile, the later use of the accumulation of clay circles marks the beginning of the spread of the cylindrical jars with flat bottom in the Far East region. Clearly, the pottery vessels belonging to the first phase of the Houtaomuga Site are not products of the earliest stage of pottery making. It does not seem to us to be a case of invention, but rather one of adoption. Prior to this, there ought to have been a long stage of exploration of pottery shaping techniques. This technological change seems to be the result of a long-term process that also involves adaptations in the economy and changes in cultural patterns, which will need to be explored further (Shelach 2012).

Fig. 5 Comparison between pottery from the Osipovka culture, the Houtaomuga phase I culture and the Xianrendong site.1. Gasya site; 2-3. Khummy site; 4. Goncharka-1 site zone D’/4-5.3p1; 5. Houtaomuga site, zone AIII pit n. 125:1; 6-8. Xianrendong Site 764E1N3 C B, 753E1N3 C A, 1482E10N11 A.

Source: 1. Derevyanko and Medvedev (1996, Fig. 81, p. 108); 2, 3. Lapshina (1999, Fig. 65-1 \& 2, p. 186); 4. Shewkomud and Yanshina (2012, Fig. 85, p. 157); 6-8 Beijing and Jiangxi (2014, pl. 13-5, 8, 16, 17 \& pl. 16-12, 13)

Through careful observation, we can see that the bottom of the pottery jar from the Gasya Site, considered to be the earliest flat-bottom pottery discovered so far, actually presents a slightly concave shape (Fig. 5-1). The pottery vessels from Houtaomuga phase I also mostly have a slightly concave bottom, and can therefore be called 'concave round bottom' vessels. This means that people from the Far East region most probably chose to make concave round bottom objects during the initial stage of pottery production, or that they chose to imitate woven containers with an almost flat bottom, and by doing so, progressively formed a pottery production tradition which differs from those of other regions.

As for decoration, patterns similar to Houtaomuga phase I pottery's comb-teeth short parallel lines and comb-teeth zigzags can be found on decoration from the pottery at the Goncharka-I (Fig. 2-18 to 24) and Ust'-Karenga-12 sites (Fig. 2-25 to 28), especially single and stepping-comb elements (Vetrov and Hommel 2017). These are the most prevalent patterns among the Houtaomuga phase I pottery. Because the upper chronological limits of these two cultures are both earlier than the remains of Houtaomuga phase I, we cannot eliminate the possibility that these two patterns of Houtaomuga phase I were influences from these two cultures. Furthermore, impressed dotted patterns made by a comb-like stamp tool or by a rolling tool later became a common decoration style on the early pottery in the Zabaykalsky (Transbaikal) Region and the Amur River Valley. Meanwhile, one cannot ignore the differences in the decorations of early pottery from Houtaomuga phase I, the Zabaykalsky Region and the Lower Amur River Valley. In the Osipovka culture, apart from a portion of the pottery from the Goncharka-I Site, which bears comb-tooth patterns, 
the pottery excavated from other sites mostly has a surface with traces of smoothing or impressions of woven fabric (Zhushchikhovskaya 1997), but no comb-toothlike decoration. The comb-tooth zigzag pattern, which is the most common on the pottery of the Ust'-Karenga culture, is only seen on a small number of sherds of Houtaomuga phase I.

\section{Discussion}

Archaeologists around the world continue to debate the factors that led to the appearance of pottery in East Asia, whether the early pottery traditions of different regions have different functions, and whether there is a correlation between the appearance of pottery and sedentism (Shelach 2012; Kuzmin 2006; Zhushchikhovskaya 2012). Considering a broader geographical frame and looking at the morphology of the bottom of the vessels, the pots from Houtaomuga phase I basically all have a flat or a slightly concave bottom, similar to those from the Osipovka culture of the lower course of the Amur River; the Nanzhuangtou Site in Xushui in northern China (Baoding et al. 1992; Hebei et al. 2010); the Zhuannian Site in Beijing (Yu et al. 1998; Yu 2002); and the Donghulin Site (Donghulin 2003; Zhao et al. 2003, 2005a; Beijing et al. 2006).

They also present clear differences with the pointed or rounded bottoms of the early pottery from the Zabaykalsky Region around Lake Baikal, the Japanese archipelago and southern China. Located at the centre of this large region of Northeast Asia, China's Northeast Plain is the area with the highest concentration of the flat-bottom cylindrical jars (tongxing guan) during the Middle and Late Neolithic (Feng 1991). The remains from Houtaomuga phase I show that this tradition of flat-bottom pottery containers begins very early, during the transition between the Late Paleolithic and the Early Neolithic.

Okladnikov very early noticed that the Neolithic of the Far East, including Northeast China, possessed a common tradition of flat-bottom pottery (Okladnikov 1950, 1964). Afterwards, researchers like Onuki (1989) and Feng Enxue (1991) successively emphasized this characteristic. The pottery from the Osipovka culture of the lower course of the Amur River and from the newly discovered culture of Houtaomuga phase I are precursors of this cultural tradition. The pottery types that first appeared in southern China, the Japanese archipelago, the Russian Far East and the Korean peninsula all mainly have rounded or pointed bottoms. So, why would two different types of bottom morphology appear in the production of the earliest pottery? Is it due to a difference in production or use habits, or is it because one is chronologically earlier than the other? Zhu Yanping points out that the round-bottom pottery appears earlier than the flat-bottom pottery. He based his hypothesis on the fact that it was difficult to find an image of a round object with a flat bottom in nature, during the stage of pottery production by imitation so, according to him, 'round pottery with a flat bottom is a purely abstract shape' (Zhu 1999). In fact, this deduction overlooks the possibility that at a very early stage, before the invention of pottery, human beings produced flat-bottom containers made of 
woven organic materials like grass or tree bark. According to modern observations of basketwork traditions in northern and southern China, certain types of basketry containers are made beginning at the centre of the bottom (an operation called 'bottom beginning' — qidi), continuing with the belly ('weaving the belly' bianbang) and finishing with the opening (binding off-shoukou) (Holmes 1980). There is often no clear curve from the bottom to the opening. The final object can have a pointed bottom, a round bottom, or a flat bottom. The so-called 'flat bottom' may be produced by constant application of pressure on the centre of the bottom during the fabrication process, by correcting the shape, or by some other method. In this way, it is possible to obtain a woven object with a flat bottom (Cai 2012; Wang 2014a, pp. 16-19). These 'flat bottom' objects have, more accurately speaking, a near-flat bottom or a concave round bottom. There was likely no real difference in the production technique between pointed bottoms, round bottoms and concave round bottoms with respect to early woven containers. It therefore seems possible that the variety of early pottery forms could well be a reflex of the pre-existing formal variance in the woven vessels which served as their prototypes.

Taking a wider perspective, the shaping technique of well-ordered fibre tempering followed by fine-clay coating echoes the traditional architectural techniques used in the construction of wattle-and-daub houses with plaited coils in northeast China (Zhang 1985, p. 93), and could link this pottery tradition to the 'architectural hypothesis' of pottery origins (Rice 1999, pp. 5-6).

During the phase of climate and environmental changes, which marked the transition between the Late Glacial and the Holocene, human groups needed to adapt to new conditions and develop new food acquisition techniques (e.g. wild plant and shellfish gathering). This led them to technological innovations such as microblade industries and pottery production, a phase which is frequently named 'Mesolithic' by some researchers (Zhushchikhovskaya 1997; Zhao 1998; Rice 1999, p. 47;

Kuzmin 2000; Peng and Zhou 2004; Valentin 2010, pp. 67-69; Mazurkevich and Dolbunova 2015).

The dates of Houtaomuga Phase I also more or less coincide with a period of exponential population growth, as pointed out by Kuzmin and Keates' analysis of a large sample of 437 radiocarbon dates in Siberia and the Russian Far East, used to arrive at a rough estimate of relative population density (Kuzmin and Keates 2005). All the evidence leads us to advance the following hypothesis: when human groups left the cave sites of the forest regions of the eastern part of the Northeast China Plain, moving west in the prairie and looking for new subsistence resources, the dense distribution of rivers and lakes and the plentiful aquatic resources of the Song-Nen Plain naturally attracted them as an ideal habitat. In order to control the stable food resources offered by the rivers and lakes, these human groups may have adopted seasonal sedentism. And the need to process and store food unsuitable for eating raw, or to roast aquatic animal food, like freshwater fish, shrimps and clams, became a strong motivating force for the appearance of pottery, causing the human groups of this region to enter a new era. It shows, at least, that these human groups 
had knowledge of clay resources and properties, had mastered firing techniques and needed new types of containers. It might also mean that the appearance of seasonal sedentary activities, or new kinds of mobility practices, could be seen as a true marker of the beginning of the Neolithic in the Song-Nen Plain as well as Northeast Asia.

\section{Conclusion}

The above analysis indicates that the remains from Houtaomuga phase I (c. 12,900-11,100 BP) are the earliest Neolithic remains discovered so far in China's northeast region; they fill the gap in the regional distribution of early pottery dating from over 10,000 BP. These remains are related, at different levels, with early Neolithic cultures from the vast surrounding area. According to technological observation, this pottery already displays a certain degree of advanced technology; it is not the product of the very initial stage of the invention of pottery. The rich resources in aquatic animals and wild plants of the Song-Nen Plain encouraged the human groups which arrived in this region to move toward seasonal sedentism and create the foundation for making pottery.

\section{Acknowledgements}

This research was made possible with the support of the grants from the Social Science

Foundation of the Chinese Government (No. 15ZDB055) and the Houtaomuga research project (No. 357121741444). This research is also part of the research project on 'Settlement distribution on the longue durée in the Jilin Province' (Jilin University, No. 450060522161). We are also grateful for the advice of Elisabeth Berger (University of Michigan) and James Williams (Renmin University, China) on the editing of this article, and to Peter Hommel for his remarks and information about Russian sites.

\section{References}

An, Z. (1989). Huanan zaoqi Xinshiqi de ${ }_{14} \mathrm{C}$ duandai he wenti [The ${ }_{14} \mathrm{C}$ dates of the Early Neolithic in South China and related problems]. Disiji уапjiu, 2, 123-133.

Baoding diqu wenwu guanlisuo, Xushui xian wenwu guanlisuo, Beijing daxue kaoguxi and Hebei daxue lishixi. (1992). Hebei Xushui xian Nanzhuangtou yizhi shijue jianbao [Preliminary report on the trial excavation of the Nanzhuangtou Site in Xushui District, Heibei]. Kaogu, 11, 961-966.

Barnes, G. L. (1999). The rise of civilization in East Asia: The archaeology of China, Korea and Japan. London: Thames \& Hudson.

Beijing daxue kaogu wenbo xueyuan and Jiangxi sheng wenwu kaogu yanjiusuo. (2014). Xianrendong yu Diaotonghuan [Xianrendong and Diaotonghuan] (pp. 76-89). Beijing: Wenwu chubanshe. Beijing daxue kaogu wenbo xueyuan and Zhengzhou shi wenwu kaogu yanjiuyuan. (2011). Henan Xinmi shi Lijiagou yizhi fajue jianbao [Preliminary report on the archaeological excavation of the Lijiagou Site in Xinmi City, Henan]. Kaogu, 4, 3-9.

Beijing daxue kaogu wenbo xueyuan, Beijing daxue kaoguxue yanjiu zhongxin and Beijing shi wenwu yanjiusuo. (2006). Beijing shi Mentougou qu Donghulin shiqian yizhi [The prehistoric site of Donghulin, in Mengtougou, Beijing City]. Kaogu, 7, 3-8.

Beijing daxue Zhongguo kaoguxue yanjiu zhongxin, Zhengzhou shi wenwu kaogu yanjiuyuan (2013). Henan Xinmi Lijiagou yizhi nanqu 2009 nian fajue baogao [Report on the 2009 excavation of the 
south zone of the Lijiagou Site at Xinmi in Henan]. Gudai wenming, 9 (pp. 208-239). Beijing:

Wenwu chubanshe.

Boaretto, E., Wu, X., Yuan, J., Bar-Yosef, O., Chu, V., Pan, Y., et al. (2009). Radiocarbon dating of charcoal and bone collagen associated with early pottery at Yuchanyan Cave, Hunan Province, China.

PNAS, 106(24), 9595-9600.

Cai, L. (2012). Laozuo moshi yu cunluo gongtongti - Jing Jiao yancun jingbian kaocha [Work mode and village community - Investigation on basketry in the villages in Beijing suburbs]. Folklore Studies, $6,123-130$.

Chen, S. (1999). Guilin Miaoyan dongxue yizhi de fajue yu yanjiu [Excavation and research on the Miaoyan Cave Site in Guilin]. In Yingede Museum, Anthropology Department of Zhongshan University and Guangdong Province Museum (Eds.), Zhongshiqi wenhua ji youguan wenti yantaohui lunwenji [Research conference on the Mesolithic cultures and related questions] (pp. 150-165). Guangzhou: Guangdong renmin chubanshe.

Chen, W. (2015). Lingnan diqu Shiqian niandai xue ji xiangguan wenti yanjiu [Research on dating and related problems in the prehistory of the Lingnan Region]. Dongnan wenhua, 6, 50-55.

Chen, W. (2016). You tao yu wu tao: Shijian zao wan haishi kongjian chayi? - Jianlun Lingnan Xinshiqi shidai zaoqi wenhua [Presence or absence of pottery: Chronological succession or spatial difference? Preliminary discussion on the Early Neolithic cultures in the Lingnan region]. Jianghan kaogu, 1, 51-58.

Cohen, D. J. (2013). The advent and spread of early pottery in East Asia: New dates and new considerations for the world's earliest ceramic vessels. Journal of Austronesian Studies, 4(2), 55-92.

Craig, O. E., Saul, H., Lucquin, A., Nishida, Y., Taché, K., Clarke, L., et al. (2013). Earliest evidence for the use of pottery. Nature, 496, 351-354.

Derevyanko, A. P., \& Medvedev, V. E. (Trans. Song Yubin). (1996). Исследования поселения Гася (предварительные результаты, 1980 г.) Gasya yizhi yanjiu - 1980 nian chubu jieguo [Research on the Gasya site - Preliminary results of 1980]. In Dongbeiya kaogu ziliao yiwenji-Eluosi zhuanhao [Collections of translated articles in Northeast Asia Archaeology - Special Issue on Russia] (pp. 1-15). Harbin: Dongbei wenwu zazhishe bianji chuban.

Dolukhanov, P., Shukurov, A., Gronenborn, D., Sokoloff, D., Timofeev, V., \& Zaitseva, G. (2005). The chronology of Neolithic dispersal in Central and Eastern Europe. Journal of Archaeological Science, $32,1441-1458$

Donghulin kaogudui. (2003). Beijing Xinshiqi zaoqi kaogu de zhongyao tupo - Donghulin ren yinqi guangfan guanzhu [Important breakthrough in Beijing Early Neolithic archaeology-The Donghulin Man attracts a large Interest]. Zhongguo wenwu bao, January 7th, 1.

Fan, X., \& Wang, G. (2012). Fujian Zhangping Qihedong yizhi fajue qude zhongda shouhuo [The important results of the excavation of the Qihedong site in Zhangping City, Fujian]. Zhongguo wenwu bao, March 3rd, 7.

Feng, E. (1991). Dongbei pingdi tongxing guan quxi yanjiu [Research on regional typology of the flat bottom cylindrical jars in the northeast]. Beifang wenwu, 4, 28-42.

$\mathrm{Fu}, \mathrm{X}$. (2012). Lingnan diqu de Xinshiqi shidai zaoqi wenhua [The Early Neolithic cultures from the Lingnan region]. Каоgи хиеbаo, 9, 37-48.

Fu, X., He, Z., Xiong, Z., \& Wang, H. (2001). Guiling diqu shiqian wenhua mianmao lunkuo chuxian [The discovery of the main features of the prehistoric cultures in Guilin region]. Zhongguo wenwu bao, April 4th, 1. 
Fujian bowuguan and Longyan shi wenhua yu chuban ju. (2013). Fujian Zhangping shi Qihedong shiqian yizhi fajue jianbao [Preliminary report on the excavation of the Qihedong prehistorical site in Zhangping City, Fujian]. Kaogu, 5, 7-19.

Fukuda, M. (2014). New insights from the study of the Yamikhta site. In Shizuo Onuki (Ed.), An archaeological study on prehistoric cultural interaction in the northern circum Japan Sea area (I): Yamikhta site excavation report (pp. 157-160). Tokyo: Tokoro Research Laboratory, Graduate School of Humanities and Sociology, University of Tokyo.

Ge, Z. (1990). Lishui Shenxiandong yiwan nian qian taopian de faxian jiqi yiyi [The discovery and significance of pottery sherds dating from over 10,000 BP. Discovered at Shenxiandong in Lishui]. Dongnan wenhua, 5, 302-303.

Gu, H., \& Yuan, J. (2006). Yuchanyan yizhi weiti luolei dui tantao gu renlei huodong tezheng de zhishi yiyi [The significance of the evidence of the activity patterns of ancient humans from the analysis of small spiral shells at the Yuchanyan Site]. Disiji yanjiu, 4, 562-570.

Guangdong Province Museum. (1961). Guangdong Wengyuan xian Qingtang Xinshiqi shidai yizhi [The Neolithic site of Qingtang in Wengyuan District, Guangdong Province]. Kaogu, 11, $585-588$.

Guangxi Zhuangzu zizhiqu wenwu gongzuodui, and Guilin shi geming weiyuanhui wenwu guanli weiyuanhui. (1976). Guangxi Guilin Zengpiyan dongxue yizhi de shijue [The test excavation of the Wengpiyan Cave Site in Guilin, Guangxi]. Kaogu, 3, 175-179, 160.

Hartz, S., Kostyleva, E., Piezonka, H., Tergberger, T., Tsydenova, N., \& Zhilin, M. G. (2012). Huntergatherer pottery and charred residue dating: New results on early ceramics in the north Eurasian forest zone. In Boaretto, E. \& Rebollo, N. R. (Eds.), Proceedings of the 6th international radiocarbon and archaeology symposium. Radiocarbon, 54, 3-4, 1033-1048.

Hayden, B. (1995). The emergence of prestige technologies and pottery. In E. K. Barnett \& J. W. Hoopes (Eds.), The emergence of pottery: Technology and innovation in ancient societies (pp. 257-265). Washington: Smithsonian Institution Press.

Hebei sheng wenwu yanjiusuo, Baoding shi wenwu ganlisuo, Xushui xian wenwu guanlisuo, and Shanxi daxue lishi wenhua xueyuan. (2010). 1997 nian Hebei Xushui Nanzhuangtou yizhi baogao [Report on the 1997 excavation of the Nanzhuangtou site in Xushui Hebei]. Kaogu xuebao, $3,361-385$.

Holmes, W. H. (1980). Textile art in relation to form and ornament. Ethnological report. Washington: Government Office Printing.

Hommel, P. (2017). What's the point? Globalization and the emergence of ceramic-using hunter-gatherers in northern Eurasia. In N. Boivin \& M. Frachetti (Eds.), Globalization and the people without history (pp. 1-29). Cambridge: Cambridge University Press.

Hommel, P., Day, P., Jordan, P., Muller, N., \& Vetrov, V. M. (2017). Changing clays: Raw material preferences in the 'Neolithic' ceramic assemblages of the Upper Vitim Basin. Proceedings of the Prehistoric Society, 83, 137-153.

Jiang, Y. (2006). Bailiandong yizhi, Miaoyan yizhi yu Xianrendong yizhi de yanjiu [Research on the Bailiandong, the Miaoyan and the Xianrendong sites]. Shiqian yanjiu, 58-67.

Jiang, Y., \& Tan, F. (2009). Dalongtan ren shengye moshi de huanjing kaoguxue fenxi [Paleoenvironmental analysis of the subsistence model of the Dalongtan ancient people]. Shiqian yanjiu, 70-79.

Jiangxi Province Museum. (1976). Jiangxi Wannian Xianrendong dongxue yizhi dier ci fajue baogao [Report on the second season of archaeological excavation of the Xianrendong site in Wannian, 
Jiangxi]. Wenwu, 12, 23-35.

Jiangxi sheng wenwu guanli weiyuanhui. (1963). Jiangxi Wannian Dayuan Xianrendong dongxue yizhi shijue [Test excavation on the cave site of Xianrendong in Dayuan, Wannian district, Jiangxi].

Kаоgи хиеbаo, 1, 1-16.

Jiangxi sheng wenwu guanli weiyuanhui. (1964). Jiangxi Wannian Dayuan Xianrendong dongxue yizhi di er ci fajue jianbao. Wenwu gongwuo ziliao, 39, 1-3.

Jiao, T. (1994). Gengxinshi mo dao Quanxinshi chu Lingnan diqu de shiqian wenhua [Prehistoric cultures from the end of the Pleistocene to the beginning of the Holocene in the area south of the Five

Ridges]. Kaogu хиеbao, 1, 1-24.

Jilin daxue Bianjiang kaogu yanjiu zhongxin, and Jilin sheng wenwu kaogu yanjiusuo. (2013). Jilin Baicheng Shuangta yizhi Xinshiqi shidai yicun [The Neolithic remains from the Shuangta site in Baicheng,

Jilin]. Каоgи хиеьао, 4, 501-538.

Jilin daxue Bianjiang kaogu yanjiu zhongxin, and Jilin sheng wenwu kaogu yanjiusuo. (2016). Jilin Da'an Houtaomuga yizhi AIII qu fajue jianbao [Preliminary excavation report on the zone AIII of the Houtaomuga Site in Da'an, Jilin]. Kaogu, 9, 3-24.

Jin, X., Chu, J., \& Wang, L. (2011). Jilin Tongyu xian Changtuozi si chu yizhi de diaocha [Survey of four sites at Changtuozi in Tongyu district, Jilin]. Beifang wenwu, 3, 3-7.

Jin, Z. (2011). Niulandong yizhi yu Guangdong Xinshiqi shidai zaoqi wenhua de fenqi [The chronology of the Early Neolithic cultures in Guangdong and the Niulandong Site]. Sichuan wenwu, 6, 22-28. Jin, Z., Zhang, Z., Qu, J., Yu, X., Kuang, M., Yi, Z., et al. (1998). Yingde Yunling Niulandong yizhi shijue jianbao [Preliminary report on the excavation of the Niulandong Site at Yunling in Yingde City]. Jiang Han kaogu, 1(14-20), 13.

Jordan, P., \& Zvelebil, M. (2009). Ex Oriente lux: The prehistory of hunter-gatherer ceramic dispersal. In P. Jordan \& M. Zvelebil (Eds.), Ceramics before farming: The dispersal of pottery among prehistoric Eurasian hunter-gatherers (pp. 33-89). Walnut Creek: Left Coast Press.

Kajiwara, H., \& Kononenko, A. V. (1997). The origin of early pottery in Northeast Asia in the context of environmental change. The origins of ceramics in East Asia and the Far East. Abstract of international symposium, 29 September-5 October 1995, Sendai, pp. 64-79.

Kang, C. (2006). Jeju Gosan-ri Sinseokgi Munhua Yeongu. Ph.D. Dissertation, Yeongnam University. Kang, C., \& O, Y. (2003). Jeju Gosan-ri Yujeok. Museum of Jeju University.

Kobayashi, T. (1983). [Introduction]. In Jomon bunka no kenkyu [Research on the Jomon Culture], vol.

3. Tokyo: Yuzankaku.

Kunikita, D., Shevkomud, I. Y., Yoshida, K., \& Matsuzaki, H. (2014). Radiocarbon dating of charred remains on pottery and analyzing food habits of the Osipovka culture, Russian Far East. In S.

Onuki (Ed.), An archaeological study on prehistoric cultural interaction in the northern circum Japan Sea area (I): Yamikhta Site excavation report (pp. 108-113). Tokyo: Tokoro Research Laboratory, Graduate School of Humanities and Sociology, University of Tokyo.

Kunikita, D., Wang, L., Onuki, S., Sato, H., \& Matsuzaki, H. (in press). Radiocarbon dating and dietary reconstruction of the Early Neolithic Houtaomuga and Shuangta sites in the Song-Nen plain, northeast China. Quaternary International.

Kuzmin, Y. V. (2000). Radiocarbon chronology of the Stone Age cultures on the Pacific coast of northeastern Siberia. Arctic Anthropology, 37(1), 120-131.

Kuzmin, Y. V. (2002). The earliest centers of pottery origin in the Russian Far East and Siberia: Review of chronology for the oldest Neolithic cultures. Documenta Praehistorica, XXIX, 37-46. 
Kuzmin, Y. V. (2006). Chronology of the earliest pottery in East Asia: Progress and pitfalls. Antiquity, 80, $362-371$

Kuzmin, Y. V. (2008). Geoarchaeology of prehistoric cultural complexes in the Russian Far East: Recent progress and problems. Bulletin of the Indo-Pacific Prehistory Association, 28, 3-10.

Kuzmin, Y. V., \& Keates, S. G. (2005). Dates are not just data: Paleolithic settlement patterns in Siberia derived from radiocarbon records. American Antiquity, 70(4), 773-789.

Kuzmin, Y. V., \& Vetrov, V. M. (2007). The earliest Neolithic complex in Siberia: The Ust-Karenga 12 Site and its significance for the neolithisation process in Eurasia (pp. 9-20). XXXIV: Documenta Praehistorica.

Lapshina, Z. S. (1999). Древности озера Хумми [The antiquities of Lake Khummi]. Khabarovsk: Priamur'e Geographic Society Press.

Liu, L. (2006). Zhiwuzhi taoqi yu shizhufa [Vegetable-fibre tempered pottery and stone-boiling techniques]. Zhongguo wenwubao, May 26th, 7.

Liu, L., \& Chen, X. (2012). The archaeology of China: From the late Paleolithic to the Early Bronze age. Cambridge: Cambridge University Press.

Liu, S., Cui, J., \& Wang, L. (in prep). Jilin Da'an Houtaomuga yizhi chutu taopian keji jiance fenxi [Technological analysis on pottery sherds from the Houtaomuga Site in Da'an, Jilin].

Liu, W. (2002). Liuzhou Dalongtan Liyuzui beiqiu yizhi de faxian yu fajue [The discovery and excavation of the Dalontan Liyuzui Site in Liuzhou]. Shiqian yanjiu, 148-150.

Liu, X., Sebillaud, P., \& Wang, L. (2016). Jilin sheng Da'an shi 2012-2013 nian quyuxing xitong diaocha jianbao [Preliminary report on the 2012-2013 regional systematic survey in Da'an City, Jilin Province]. Bianjiang kaogu yanjiu, 19, 27-45.

Liuzhou City Museum, and Guangxi zhuangzu zizhiqu wenwu gongzuodui. (1983). Liuzhou shi Dalongtan Liyuzui Xinshiqi shidai beiqiu yizhi [The Neolithic shell mound site of Dalongtan Liyuzui in Linzhou City]. Kaogu, 9, 769-774.

Lü, L. (2008). Guilin diqu Gengxinshi moqi dao Quanxinshi chuqi de Shiqian jingji he wenhua fazhan [Prehistorical economic and cultural development from the end of the Pleistocene to the beginning of the Holocene in the Huilin region]. Kaoguxue yanjiu, 7, 333-353.

Lü, P., \& Fu, X. (2010). Dingsishan yizhi chutu bangdao de dongwu kaoguxue yanjiu [Archeozoological research on the shell knives discovered at the Dingsishan Site]. Nanfang wenwu, 4, 48-54.

MacNeish, R. S., Cunnar, G., Zhao, Z., \& Libby, J. G. (1998). Re-revised second annual report of the sino-American Jiangxi (PRC) Origin of Rice Project SAJOR (p. 39). Andover: Andover Foundation for Archaeological Research, Ltd.

MacNeish, R. S., \& Libby, J. G. (Eds.). (1995). Origins of rice agriculture. The preliminary report of the Sino-American Jiangxi (PRC) Project SAJOR. Publications in Anthropology No.13 (p. 87). El Paso: El Paso Centennial Museum, University of Texas.

Mazurkevich, A., \& Dolbunova, E. (2015). The oldest pottery in hunter-gatherer communities and models of Neolithisation of Eastern Europe. Documenta Praehistorica, 62, 13-66.

McKenzie, H. (2009). Review of early hunter-gatherer pottery in eastern Siberia. In P. Jordan \& M. Zvelebil (Eds.), Ceramics before farming: The dispersal of pottery among prehistoric Eurasian huntergatherers (pp. 167-208). Walnut Creek: Left Coast Press.

Medvedev, V. E. (1995). К проблеме начального и раннего неолита на Нижнем Амуре [About the problem of Initial and Early Neolithic in the Lower Amur River Basin]. In A. P. Derevianko \& V. E. Larichev (Eds.), Обозрение результатов полевых и лабораторных исследований 
археологов, этнографов и антропологов Сибири и Дальнего Востока в 1993 году. [A review of the results of field and laboratory research of archaeologists, ethnographers and anthropologists of Siberia and Far East in 1993] (pp. 228-237). Novosibirsk: Izdatelstvo Instituta Arkheologii i Etnografii SORAN.

Mei, H., \& Xie, F. (2002). Huabei Jiushiqi shidai de guodu: Nihewan pendi Yangyuan Yujiagou yizhi (1990-1999) [The transition of the end of the Paleolithic in northern China: The Yujiagou Site in Yangyuan in the Nihewan Basin (1990-1999)] (pp. 103-111). Zhongguo shinian bai da kaogu xin faxian, 1, Beijing: Wenwu chubanshe.

Merrett, D. C., Zhang, H., Xiao, X., Zhang, Q., Wei, D., Wang, L., et al. (2015). Enamel hypoplasia in northeast China: Evidence from Houtaomuga. Quaternary International. https ://doi.org/10.1016/j. quain t.2015.06.004.

Okladnikov, A. Р. (1950). Неолит и бронзовый век Прибайкалья. [Neolithic and Bronze Age around the Baikal region]. Материаль и исследования по археологии CCCP [Data and Research on Soviet Archaeology], 18.

Okladnikov, А. Р. (1964). Советский Дальний Восток в свете новейших достижений археологии [The Soviet Far East in the light of new results of Soviet archaeology]. Bonpocbl uстории [Historical Questions], 1, 44-57.

Onuki, S. (1989). Dongbeiya zhou zhong de Zhongguo Dongbei diqu yuanshi wenhua [The primitive cultures of China northeast region in continental Northeast Asia]. In Qingzhu Su Binqi kaogu wushiwu nian lunwenji [Collection of Archaeology Articles in Honor of the 55th Anniversary of Su Binqi] (pp. 38-64). Beijing: Wenwu chubanshe.

Pearson, R. (2006). Jomon hot spot: Increasing sedentism in southwestern Japan in the Incipient Jomon (14,000-9250 Cal. BC) and Earliest Jomon (9250-5300 Cal. BC) periods. World Archaeology, 38(2), 239-258.

Peng, S. (1981). Youguan Huanan Xinshiqi zaoqi Wannian Xianrendong wenhua de jige wenti [Some questions on the Early Neolithic cultures of Xianrendong in South China]. Jiangxi lishi wenwu, 3, 9-18.

Peng, S., \& Zhou, G. (2004). Jiangxi Wannian Xianrendong yu Diaotonghuan yizhi: Jiushiqi shidai xiang Xinshiqi shidai guodu moshi de ge an yanjiu [The Xianrendong and the Diaotonghuan sites in Jiangxi: A case study on the model of transition between Paleolithic and Neolithic]. Nongye kaogu,

8, 29-39.

Rice, P. M. (1999). On the origins of pottery. Journal of Archaeological Method and Theory, 6(1), 1-54. Schiffer, M. B., Skibo, J. M., Boelke, T. C., Neupert, M. A., \& Aronson, M. (1994). New perspectives on experimental archaeology: Surface treatments and thermal response of the clay-cooking pot. American Antiquity, 59(2), 197-217.

Shelach, G. (2000). The earliest Neolithic cultures of northeast China: Recent discoveries and new perspectives on the beginning of agriculture. Journal of World Prehistory, 14(4), 363-413.

Shelach, G. (2012). On the invention of pottery. Science, 336, 1644-1645.

Shelach, G., \& Teng, M. (2013). Earlier Neolithic economic and social systems of the Liao River region, northeast China. In A. Underhill (Ed.), A companion to Chinese archaeology (pp. 37-54). Oxford: Blackwell.

Shewkomud, I. Y., \& Kuzmin, Y. V. (2009). Хронология каменного века нижнего приамурья (дальний восток России) [The chronology of the Stone Age Lower Amur (Russian Far East)]. Культурная хронология и другие проблемы в исследования древностей востока Азии [Cultural chronology 
and other problems in the study of antiquities east Asia] (pp. 13-14). Khabarovsk.

Shewkomud, I. Y., and Yanshina, O. V. (2012). Начало неолита в Приамуръе: Поселение Гончарка-1 [Beginning of the Neolithic in the Amur River Basin: The Goncharka-1 Site] (pp. 148-173). SaintPetersburg: MAERAS.

Skibo, J. M. (2013). Understanding pottery function. New York: Springer.

Skibo, J. M., \& Schiffer, M. B. (2008). People and things: A behavioral approach to material culture.

New York: Springer.

Skibo, J. M., Schiffer, M. B., \& Reid, K. C. (1989). Organic-tempered pottery: An experimental study. American Antiquity, 54(1), 122-146.

Sun, Q. (2002). Xianrendong taoguan yu Xianrendong yizhi: jiantan duiqi niandai de renshi guocheng [The pottery jar of Xianrendong and the Xianrendong Site: Review of the research process on its chronology]. Zhongguo lishi wenwu, 4, 43-50.

Tan, F. (2002). Yongning xian Dingsishan yizhi de zangsu shishi [Essay on Interpretation of the funerary customs at the Dingsishan Site in the Yongning district]. Lingnan kaogu yanjiu, 2, 107-110.

Tan, F. (2010). Guangxi Yongning Dingsishan Shiqian quzhi zang yu shijie zang de kaocha [Investigation into the prehistoric flexed burials and the dismemberment burials at Dingsishan in Yongning in Guangxi]. Nanfang wenwu, 2, 74-80.

Tang, Z., Liu, W., \& Wang, L. (in prep). Jilin Da'an Houtaomuga yizhi baofen fenxi yu gu huanjing chubu yanjiu [Preliminary research on pollen analysis and paleoenvironment on the Houtaomuga Site in Da'an, Jilin Province].

Testart, A. (1982). The significance of food storage among hunter-gatherers. Current Anthropology, 23, $523-537$.

Tsutsumi, T. (Transl. Yue Xiaohua). (2000). Riben liedao wan Bingqi renlei dui huanjing de shying he taoqi qiyuan [Human adaptation to the environment during the Late Glacial Period in the Japanese Archipelago and the origins of pottery]. In Daozuo, taoqi he dushi de qiyuan [The origins of rice, pottery and cities] (pp. 65-80). Beijing: Wenwu chubanshe.

Tsydenova, N., \& Piezonka, H. (2015). The transition from the Late Paleolithic to the Initial Neolithic in the Baikal Region: Technological aspects of the stone industries. Quaternary International, 355, $101-113$.

Underhill, A. P. (1997). Current Issues in Chinese Neolithic archaeology. Journal of World Prehistory, $11(2), 103-160$.

Valentin, B. (2010). Le Paléolithique. Que sais-je? Paris: PUF.

Vetrov, V. M. (1985). Керамика усть-каренгской культуры на Витиме [The pottery of Ust-Karenga culture in the Vitim River]. In P. B. Konovalov (Ed.), Древнее Забайкалье и его культурные связи [The ancient Baikal region and its cultural connections] (pp. 123-130). Novosibirsk: Nauka. Vetrov, V. M., \& Hommel, P. (2017). Vessels on the Vitim: 'Neolithic' ceramics of the Upper Vitim Basin. In K. Gibbs \& P. Jordan (Eds.), Circumpolar ceramics: Hunter-Gatherer pottery technologies and the foraging spectrum. Cambridge: Cambridge University Press.

Wang, H., Shen, G., \& Fang, Y. (2006). Jiangsu Lishui Shenxiandong dongwu huashi de youxi niandai [Uranium/thorium isotope dating of the animal fossils from Shenxiandong in Lishui, Jiangsu].

Dongnan wenhua, 3, 6-9.

Wang, L., Huo, D., Shi, X., \& Sebillaud, P. (2012). Jilin Da'an Houtaomuga yizhi fajue qude zhongyao shouhuo [Important results from the excavation of the Houtaomuga Site in Da'an], Zhongguo wenwu bao, August 17th, 1. 
Wang, L., Huo, D., Zhao, J., \& Liu, X. (2013). Jilin Da'an Houtaomuga yizhi [The Houtaomuga Site at Da'an, Jilin Province]. 2012 Zhongyao kaogu faxian (pp. 2-7). Beijing: Wenwu chubansh.

Wang, L., Sebillaud, P., \& Huo, D. (2016). Da'an Houtaomuga yizhi de fajue fangfa, jishu yu jilu shouduan de xin changshi [Excavation of Houtaomuga Site in Da'an City: New methods, techniques and recording]. Jilin daxue shehui kexие хиеbao, 1, 113-119.

Wang, X. (1995). The occurrence of pottery in China and the development of technology. Toadzia Kekutonodoku no Kigaen [The origin of ceramics in Eastern Asia] (pp. 77-92). Sendai: Tohoku Fukushi

Press.

Wang, X. (2013). Lijiagou yizhi yu Zhongyuan nongye de qiyuan [The Lijiagou Site and the origin of agriculture in the Central Plain]. Zhongguo nongshi, 6, 13-20.

Wang, Y. (2014a). Jiangnan chuantong zhubian qiju de sheji fangfa yu zaisheng yutu yanjiu [The research on design methods and regenerate ways about Jiangnan traditional bamboo weaving utensils]. Master Dissertation of Jiangnan University.

Wang, Y. (2014b). Xinmi Lijiagou yizhi yanjiu jinzhan ji xiangguan wenti. Zhongyuan wenwu, 1, $20-24$.

Wu, R., Deng, Z., Zhang, Z., Li, J., Peng, S., \& Liu, S. (2005). Jiangxi Wannian Xianrendong yizhi chutu taopian de kexue jishu yanjiu [Scientific techniques research on the pottery sherds excavated from the Xianrendong Site in Wannian, Jiangxi]. Kaogu, 7, 62-69.

Wu, X. (2012). Zhongguo Nanfang zaoqi taoqi de niandai yiji Xinshiqi shidai biaozhi de wenti [Chronology of early pottery of southern China and the problem of indicators of the Neolithic]. Kaoguxue уапjiu, 9, 49-68.

Wu, X., Boaretto, E., Yuan, J., Bar-Yosef, O., Pan, Y., \& Qu, X. (2012a). Hunan Daoxian Yuchanyan yizhi zaoqi taoqi jiqi diceng duiji de tan shisi niandai yanjiu [Research on the radiocarbon dating of the deposit and early pottery at the Yuchanyan Site in Daoxian district, Hunan]. Nanfang wenwu, 3, 7-15.

Wu, X., Zhang, C., Goldberg, P., Cohen, D., Pan, Y., Arpin, T., et al. (2012b). Early pottery at 20,000 years ago in Xianredong Cave, China. Science, 336, 1696-1700.

Xia, N. (1977). Tan 14 ceding niandai he Zhongguo shiqian kaoguxue [

${ }_{14} \mathrm{C}$ datation and Chinese prehistorical

archaeology]. Kaogu, 4, 217-232.

Xiao, X. (2014). Jilin Da'an Houtaomuga yizhi rengu yanjiu [Research on the human remains of the Houtaomuga Site in Da'an, Jilin]. Ph.D. dissertation. Changchun: Jilin University.

Yan, W. (1987). Zhongguo shiqian wenhua de tongyixing yu duoyangxing [The unity and the diversity of the prehistoric cultures in China]. Wenwu, 3, 38-50.

Yanshina, O. V. (2014). Early Neolithic potteries from the Yamikhta Site. In O. Shizuo (Ed.), An archaeological study on prehistoric cultural interaction in the northern circum Japan Sea area (I): Yamikhta Site excavation report (pp. 141-152). Tokyo: Tokoro Research Laboratory, Graduate School of Humanities and Sociology, University of Tokyo.

Yingde City Museum, Zhongshan daxue renleixue xi, and Guangdong sheng wenwu kaogu yanjiusuo. (1999). Yingde Yunling Niulandong yizhi [The Niulandong Site at Yunling in Yingde]. In Yingde shiqian kaogu baogao [Report on prehistorical archaeology in Yingde] (pp. 1-122). Guangzhou: Guangdong renmin chubanshe.

Yu, J. (2002). Cong Beijing Zhuannian yizhi de faxian kan woguo Huabei diqu Xinshiqi shidai zaoqi wenhua de tezheng [The characteristics of the Early Neolithic culture in northern China seen from the discovery of the Zhuannian Site in Beijing]. Beijing wenwu yu kaogu, 5, 37-43. 
Yu, J., Li, Z., Yang, X., \& Li, J. (1998). Beijing Zhuannian Xinshiqi shidai zaoqi yizhi de faxian [The discovery of the Zhuannian Site from the Early Neolithic, Beijing]. Beijing wenbo, 3, 2-4.

Yu, W. (1991). Zhongguo lishi wenhua de diantang [The temple of China's history and culture]. Zhongguo lishi bowuguan guankan, 15-16, 4-6.

Yuan, J. (2000). Hunan Daoxian Yuchanyan 1 wannian yiqian de daogu he taoqi [Rice and pottery anterior to 10,000 years BP from the Yuchanyan-1 Site in Dao district in Hunan Province]. Daozuo,

taoqi he dushi de qiyuan [The origins of rice, pottery and cities] (pp. 31-41). Beijing: Wenwu chubanshe.

Yuan, J. (2013). Hunan Jiushiqi shidai wenhua yu Yuchanyan yizhi [Paleolithic culture in Hunan and the site of Yuchanyan]. Changsha: Yuelu shushe.

Zhang, H., Merrett, D., Xiao, X., Zhang, Q., Wei, D., Wang, L., et al. (2015). A comparative study of oral health in three Late Bronze Age populations with different subsistence practices in North China. Quaternary International. https ://doi.org/10.1016/j.quain t.2015.05.029.

Zhang, M., Zhu, X., Tan, J., Wu, X., \& Cao, J. (2011). Guilin Zengpiyan dongxue de xingcheng, yanhua ji gu renlei wenhua yizhi duiji qianyi [Primary research on the formation and development of Zengpiyan Cave and the ancient cultural deposit at the Zengpiyan archaeological site, Guilin, China]. Diqiu yu huanjing, 39(3), 305-312.

Zhang, Y. (1985). Jilin minju [Traditional domestic architecture in Jilin]. Beijing: Zhongguo jianzhu gongye chubanshe.

Zhang, Z. (1989). Zengpiyan dongxue yizhi jiqi niandai qianxi [The Zengpiyan Cave Site and preliminary analysis on its chronology]. Jiangxi wenwu, 1, 1-11.

Zhao, C. (1998). New achievements in the study on the transitional period from the Palaeolithic to the Neolithic in China. Documenta Praehistorica, 25, 27-36.

Zhao, C., Wang, T., Yuan, X., Cui, T., Yu, J., \& Guo, J. (2005a). Beijing Donghulin yizhi fajue zai huo fengshuo chengguo [The excavation of the Donghulin Site in Beijing obtained new important results]. Zhongguo wenwu bao, December 30th, 1.

Zhao, C., \& Wu, X. (2000). Zhongguo zaoqi taoqi de faxian, niandai ceding ji zaoqi zhitao gongyi de chubu tantao [Preliminary discussion on the discovery, chronology and manufacturing techniques of the early pottery in China]. Taoci xuebao, 21(4), 228-234.

Zhao, C., \& Wu, X. (2003). Zhongguo zaoqi taoqi de faxian ji xiangguan wenti de taolun [Discussion on the discovery of Chinese early ceramics and related questions]. Kaoguxue yanjiu, 5-1, 95-104.

Zhao, C., Yu, J., \& Wang, T. (2003). Beijing Donghulin Xinshiqi shidai zaoqi yizhi huo zhongyao faxian [Important discoveries at the Early Neolithic site of Donghulin, Beijing]. Zhongguo wenwu bao, May 9th, 1.

Zhao, H., Wang, L., Xia, H., \& Wang, C. (2010). Dongbei yuliexing Xinshiqi shidai wenhua de ge'an: Jilin Tongyu Changtuozi III hao didian xishiqi de faxian yu yanjiu [The case of northeast fishing-hunting type Neolithic Culture: Discovery and research on the microliths at the Changtuozi3 Site in Tongyu, Jilin] (pp. 20-35). Zhongguo kaoguxue di shier ci nianhui lunwenji. Beijing: Wenwu chubanshe.

Zhao, Z., Lü, L., \& Fu, X. (2005b). Guangxi Yongning xian Dingsishan yizhi chutu zhiguishi de fenxi yu yanjiu [Analysis and research on the vegetable silica excavated from the Dingsishan Site in Yongning district, Guangxi]. Kaogu, 11, 76-84.

Zhejiang sheng wenwu kaogu yanjiusu/Pujiang District Museum. (2007). Zhejiang Pujiang xian 
Shangshan yizhi fajue jianbao [Preliminary report on the excavation of the Shangshan Site in Pujiang district in Zhejiang]. Kaogu, 9, 7-18.

Zheng, Y., \& Jiang, L. (2007). Shangshan yizhi chutu de gu dao yicun jiqi yiyi [Excavated rice remains from the Shangshan Site and its significance]. Kaogu, 9, 19-25.

Zhengzhou shi wenwu kaogu yanjiuyuan/Beijing daxue kaogu wenbo xueyuan. (2011). Xinmi Lijiagou yizhi fajue de zhuyao shouhuo [Important discoveries at the archaeological excavation of the Lijiagou Site in Xinmi]. Zhongyuan wenwu, 1, 4-6, 39.

Zhengzhou shi wenwu kaogu yanjiuyuan/Beijing daxue Zhongguo kaoguxue yanjiu zhongxin. (2013).

Henan Xinmi Lijiagou yizhi beiqu 2009 nian fajue baogao [Report on the 2009 excavation of the north zone of the Lijiagou Site at Xinmi in Henan] (pp. 177-207). Gudai wenming, 9. Beijing: Wenwu chubanshe.

Zhongguo shehui kexueyuan Kaogu yanjiusuo Guangxi gongzuodui, Guangxi Zhuangzu zizhiqu wenwu gongzuodui/Nanning City Museum. (1998). Guangxi Yongning xian Dingsishan yizhi de fajue [The excavation of the Dingsishan Site in Yongning district, Guangxi Province].

Kaogu, 11, 11-33.

Zhongguo shehui kexueyuan Kaogu yanjiusuo, Guangxi Zhuangzu zizhiqu wenwu gongzuodui, Guilin Zengpiyan Site Museum/Guilin shi wenwu gongzuodui. (2003). Guilin Zengpiyan [The Zengpiyan Site in Guilin]. Beijing: Wenwu chubanshe.

Zhou, G. (1994). Zai lun Bailiantong wenhua [Re-discussing the culture of Bailiandong]. In Zhong Ri gu renlei yu Shiqian wenhua yuanyuan guanxi guoji xueshu yantaohui lunwenji [Proceedings of the International Conference on the relations and origins of the ancient humans and prehistoric cultures in China and Japan] (pp. 203-264). Beijing: Zhongguo guoji guangfan chubanshe.

Zhu, Y. (1999). Zhongguo taoqi qiyuan jieduan ji xiangguan wenti [The stage of the origins of pottery in China and related questions]. In Z. Xu \& Z. Zhang (Eds.), Zhongguo kaoguxue de kua shiji fansi [Rethinking Chinese archaeology on the eve of a new century]. Shangwu yinshuguan: Beijing. Zhushchikhovskaya, I. S. (1997). On early pottery-making in the Russian Far East. Asian Perspectives, $36(2), 159-174$.

Zhushchikhovskaya, I. S. (2001). История керамики Восточной Азии. (Учеб. пособие) [Нistory of East Asian Ceramic]. Vladivostock: Vladivostock Gosudarstvennyj Universitet Ekonomiki i Servisi.

Zhushchikhovskaya, I. S. (2012). The most ancient ceramics: The course of technological innovation. Anthropology and Archaeology of Eurasia, 51, 62-78.

Publisher's Note Springer Nature remains neutral with regard to jurisdictional claims in published maps and institutional affiliations. 